\title{
The application of Industry 4.0 technologies in sustainable logistics: a systematic literature review (2012-2020) to explore future research opportunities
}

\author{
Xu Sun ${ }^{1} \cdot$ Hao Yu ${ }^{1}$ (D) Wei Deng Solvang ${ }^{1} \cdot$ Yi Wang $^{2} \cdot$ Kesheng Wang $^{3}$
}

Received: 9 September 2021 / Accepted: 18 November 2021 / Published online: 10 December 2021

(c) The Author(s) 2021

\begin{abstract}
Nowadays, the market competition becomes increasingly fierce due to diversified customer needs, stringent environmental requirements, and global competitors. One of the most important factors for companies to not only survive but also thrive in today's competitive market is their logistics performance. This paper aims, through a systematic literature analysis of 115 papers from 2012 to 2020, at presenting quantitative insights and comprehensive overviews of the current and future research landscapes of sustainable logistics in the Industry 4.0 era. The results show that Industry 4.0 technologies provide opportunities for improving the economic efficiency, environmental performance, and social impact of logistics sectors. However, several challenges arise with this technological transformation, i.e., trade-offs among different sustainability indicators, unclear benefits, lifecycle environmental impact, inequity issues, and technology maturity. Thus, to better tackle the current research gaps, future suggestions are given to focus on the balance among different sustainability indicators through the entire lifecycle, human-centric technological transformation, system integration and digital twin, semi-autonomous transportation solutions, smart reverse logistics, and so forth.
\end{abstract}

Keywords Sustainable logistics · Green logistics · Industry 4.0 $\cdot$ Smart technology $\cdot$ Literature review $\cdot$ Bibliometric analysis

\section{Introduction}

With the increasing concerns on environmental pollution, resource depletion, and climate change from the whole society, enterprises must transform their businesses and operations into more sustainable ways (Rauter et al. 2017). Recent studies have shown that more focus and investments on enterprises' sustainable practices not only help them to build up a socially responsible image but also

Responsible Editor: Philippe Garrigues

Hao Yu

hao.yu@uit.no

1 Department of Industrial Engineering, UiT-The Arctic University of Norway, Narvik, Norway

2 School of Business, University of Plymouth, Plymouth, Devon, UK

3 Department of Mechanical and Industrial Engineering, Norwegian University of Science and Technology, Trondheim, Norway improve their overall sustainable performance in economic and environmental dimensions (Allaoui et al. 2019). Logistics links different operations and players within a supply chain and is a vital part that largely determines a company's overall effectiveness and resource efficiency (Qaiser et al. 2017). Managing a logistics system involves several related activities, i.e., warehousing, inventory handling, information services, and transportation, and any decisions may influence a large number of stakeholders in either positive or negative ways (Murphy and Poist 2003). The effectiveness and sustainability of a logistics system determine the long-term competitiveness and the success of an enterprise. Therefore, new methods are investigated by both academia and industrial practitioners to improve the economic, environmental, and social sustainability of logistics activities.

The recent technological advancement and innovation of Industry 4.0 have provided new opportunities for enterprises to achieve value creation and proposition through satisfying individualized customer demands responsively and cost-effectively (Wang et al. 2017). This has not only 
led to a shift of the manufacturing paradigm but also drastically affected the way of logistics operations toward a high level of digitalization, connectivity, intelligence, integration, and responsiveness (Winkelhaus and Grosse 2020). Even though Industry 4.0 provides new opportunities for enterprises to enhance their sustainable logistics practices, the operational transformation by adopting these new technologies has, however, never been a painless endeavor, which may also encounter structural resistance at both intra- and inter-enterprise levels (Sony and Naik 2019). Thus, a systematic literature analysis is important to provide useful implications into the advantages and challenges of adopting new technologies in sustainable logistics, which can help with a successful transformation of a company in the coming digital era.

Previous literature reviews have provided comprehensive insights into sustainable logistics planning (Brandenburg et al. 2014; Qaiser et al. 2017), green and sustainable logistics practices (Ren et al. 2020; Dey et al. 2011; Martins et al. 2020), sustainable freight transport (Nenni et al. 2019; Álvarez and de la Calle 2011), and knowledge management in sustainable logistics (Evangelista and Durst 2015). To improve the intelligence, agility, and efficiency of logistics activities, recent studies have put predominant emphasis on the adoption of new technologies, e.g., big data analytics (Chalmeta and Santos-deLeón 2020), blockchain (Reddy et al. 2021), artificial intelligence (AI) (Riahi et al. 2021; Tirkolaee et al. 2021), internet of things (IoT) (Tijan et al. 2019), and additive manufacturing (AM) (Khorram Niaki and Nonino 2017). This trend has led to the new architecture of Logistics 4.0 (Wang 2016). Besides, several recent reviews have discussed the connection between Industry 4.0 and general sustainable practices (Roblek et al. 2020).

Table 1 shows the comparison of recent literature reviews related to Industry 4.0, sustainability, and logistics. As shown, the research focus has been predominantly given to the general sustainability and supply chain issues related to Industry 4.0. However, there is still a lack of systematic analyses focusing on linking sustainable logistics practices with different Industry 4.0 technologies. Logistics is traditionally a labor-intensive industry, which experiences significant changes in this digital transformation, and both positive and negative impacts on the economic, environmental, and social sustainability need thus to be better understood. Besides, the use of both bibliometric analysis and content analysis has not been fully exploited. Bibliometric analysis is a quantitative method that shows the network data visualization of the inter-connections of different literature in several dimensions, but it has been rarely used in the literature reviews of Industry 4.0 and sustainability, particularly in combination with content analysis.
Therefore, as shown in Fig. 1, this paper aims at filling the literature gap by conducting a systematic literature review to illustrate the current and future research landscapes of sustainable logistics in the Industry 4.0 era. The contributions are summarized as follows:

1. Using both bibliometric analysis and content analysis, we thoroughly explore the current research landscape that links sustainable logistics practices with various Industry 4.0 technologies.

2. We analyze both opportunities and challenges of adopting Industry 4.0 technologies in logistics sectors related to economic, environmental, and social sustainability.

3. We suggest nine future research directions to fill the current research gaps.

4. From the practical perspective, the discussions provide some successful examples of Industry 4.0 enabled transformation of logistics systems.

Following the introduction, the "Theoretical background" section gives the theoretical background of sustainable logistics and Industry 4.0. The "Research method" section presents the research method. The "Bibliometric analysis" and "Content analysis" sections provide the bibliometric analysis and content analysis. The opportunities, challenges, and future research suggestions are discussed in the "Discussions" section. Finally, the "Conclusions" section concludes the paper.

\section{Theoretical background}

\section{Sustainable logistics}

The word logistics appeared more than a century ago and was originally associated with the movement of troops and military supplies (Stevenson 2010). Over time, this word has been widely used to broadly describe the movement of physical goods among different locations (Lummus et al. 2001). Logistics deals with the entire cycle including pre-production, in-production, and post-production activities (Cavinato 1982). To fulfill customer needs at a satisfactory level, logistics aims at implementing a set of decisions including the purchase of raw materials, parts, and components, the handling and storage of inventories, and the transportation of goods from one location to another. The effectiveness and efficiency of the logistics system largely determine an enterprise's performance in cost, customer satisfaction, and profitability. Recently, a concept called supply chain management has been used interchangeably to depict several logistics activities, but the scopes of the two words are not overlapped with each 
Table 1 Relevant literature reviews related to Industry 4.0, sustainability, and logistics

\begin{tabular}{|c|c|c|c|c|c|c|c|c|c|}
\hline \multirow[t]{2}{*}{ Papers } & \multicolumn{2}{|c|}{ Research method } & \multicolumn{2}{|c|}{ Sample selection } & \multirow{2}{*}{$\begin{array}{l}\text { Research focus } \\
\text { and perspectives }\end{array}$} & \multicolumn{4}{|l|}{ Keywords } \\
\hline & $\begin{array}{l}\text { Biblio- } \\
\text { metric } \\
\text { analysis }\end{array}$ & $\begin{array}{l}\text { Content } \\
\text { analy- } \\
\text { sis }\end{array}$ & Horizon & Sample size & & Industry 4.0 & Sustainability & Logistics & Supply chain \\
\hline $\begin{array}{l}\text { Davarzani et al. } \\
\text { (2016) }\end{array}$ & $\sqrt{ }$ & & 1975-2014 & 338 & $\begin{array}{l}\text { Green and sustain- } \\
\text { able maritime } \\
\text { logistics }\end{array}$ & & $\sqrt{ }$ & $\sqrt{ }$ & \\
\hline Bag et al. (2018) & & $\sqrt{ }$ & 1998-2017 & 53 & $\begin{array}{l}\text { Industry } 4.0 \text { ena- } \\
\text { blers of supply } \\
\text { chain sustain- } \\
\text { ability }\end{array}$ & $\sqrt{ }$ & $\sqrt{ }$ & & $\sqrt{ }$ \\
\hline $\begin{array}{l}\text { Ranieri et al. } \\
\text { (2018) }\end{array}$ & & $\sqrt{ }$ & 2012-2016 & 24 & $\begin{array}{l}\text { Innovative last- } \\
\text { mile delivery } \\
\text { systems }\end{array}$ & & & $\sqrt{ }$ & \\
\hline $\begin{array}{l}\text { Kazemi et al. } \\
\text { (2019) }\end{array}$ & $\sqrt{ }$ & $\sqrt{ }$ & 2000-2017 & 94 & $\begin{array}{l}\text { Reverse logistics } \\
\text { and closed-loop } \\
\text { supply chain }\end{array}$ & & & $\sqrt{ }$ & $\sqrt{ }$ \\
\hline Nenni et al. (2019) & & $\sqrt{ }$ & 1997-2018 & 93 & $\begin{array}{l}\text { Sustainability of } \\
\text { urban freight } \\
\text { transport }\end{array}$ & & $\sqrt{ }$ & & \\
\hline Tijan et al. (2019) & & $\sqrt{ }$ & Until 2018 & - & $\begin{array}{l}\text { Blockchain } \\
\text { technology in } \\
\text { logistics }\end{array}$ & & & $\sqrt{ }$ & \\
\hline $\begin{array}{l}\text { Manavalan and } \\
\text { Jayakrishna } \\
(2019)\end{array}$ & & $\sqrt{ }$ & 2009-2018 & - & $\begin{array}{l}\text { IoT embedded sus- } \\
\text { tainable supply } \\
\text { chain }\end{array}$ & $\sqrt{ }$ & & & $\sqrt{ }$ \\
\hline $\begin{array}{l}\text { Martins et al. } \\
\text { (2020) }\end{array}$ & & $\sqrt{ }$ & Until 2019 & 45 & $\begin{array}{l}\text { Sustainable logis- } \\
\text { tics considering } \\
\text { TBL }\end{array}$ & & $\sqrt{ }$ & $\sqrt{ }$ & \\
\hline Ren et al. (2020) & $\sqrt{ }$ & $\sqrt{ }$ & 1999-2019 & 306 & $\begin{array}{l}\text { Green and sustain- } \\
\text { able logistics }\end{array}$ & & $\sqrt{ }$ & $\sqrt{ }$ & $\sqrt{ }$ \\
\hline $\begin{array}{l}\text { Chalmeta and } \\
\text { Santos-deLeón } \\
(2020)\end{array}$ & $\sqrt{ }$ & & 2009-2019 & 87 & $\begin{array}{l}\text { Industry } 4.0 \text { and } \\
\text { big data in sus- } \\
\text { tainable supply } \\
\text { chain practices }\end{array}$ & $\sqrt{ }$ & $\sqrt{ }$ & & $\sqrt{ }$ \\
\hline $\begin{array}{r}\text { Winkelhaus and } \\
\text { Grosse (2020) }\end{array}$ & & $\sqrt{ }$ & $2005-2018$ & 114 & $\begin{array}{l}\text { Industry } 4.0 \text { and } \\
\text { logistics }\end{array}$ & $\sqrt{ }$ & & $\sqrt{ }$ & \\
\hline $\begin{array}{l}\text { Roblek et al. } \\
\text { (2020) }\end{array}$ & & $\sqrt{ }$ & 2010-2020 & 173 & $\begin{array}{c}\text { Industry } 4.0 \text { and } \\
\text { sustainability }\end{array}$ & $\sqrt{ }$ & $\sqrt{ }$ & & \\
\hline $\begin{array}{l}\text { Ejsmont et al. } \\
\text { (2020) }\end{array}$ & $\sqrt{ }$ & & 2011-2020 & 162 & $\begin{array}{l}\text { Sustainability and } \\
\text { Industry } 4.0\end{array}$ & $\sqrt{ }$ & $\sqrt{ }$ & & \\
\hline $\begin{array}{l}\text { Ghobakhloo } \\
\text { (2020) }\end{array}$ & & $\sqrt{ }$ & 2012-2019 & 72 & $\begin{array}{c}\text { Industry } 4.0 \text { and } \\
\text { sustainability }\end{array}$ & $\sqrt{ }$ & $\sqrt{ }$ & & \\
\hline $\begin{array}{l}\text { Furstenau et al. } \\
\text { (2020) }\end{array}$ & $\sqrt{ }$ & & 2010-2019 & 894 & $\begin{array}{c}\text { Industry } 4.0 \text { and } \\
\text { sustainability }\end{array}$ & $\sqrt{ }$ & $\sqrt{ }$ & & \\
\hline $\begin{array}{l}\text { Birkel and Müller } \\
\text { (2020) }\end{array}$ & & $\sqrt{ }$ & 2011-2019 & 55 & $\begin{array}{l}\text { Industry } 4.0 \text { for } \\
\text { sustainable } \\
\text { supply chain } \\
\text { management }\end{array}$ & $\sqrt{ }$ & $\sqrt{ }$ & & $\sqrt{ }$ \\
\hline $\begin{array}{l}\text { Margherita and } \\
\text { Braccini (2020) }\end{array}$ & & $\sqrt{ }$ & 2009-2019 & 18 & $\begin{array}{l}\text { Industry } 4.0 \\
\text { organizational } \\
\text { impacts on } \\
\text { sustainability }\end{array}$ & $\sqrt{ }$ & $\sqrt{ }$ & & \\
\hline Beier et al. (2020) & & $\sqrt{ }$ & 2013-2021 & 51 & $\begin{array}{c}\text { Industry } 4.0 \text { and } \\
\text { socio-technical } \\
\text { sustainability }\end{array}$ & $\sqrt{ }$ & $\sqrt{ }$ & & \\
\hline
\end{tabular}


Table 1 (continued)

\begin{tabular}{|c|c|c|c|c|c|c|c|}
\hline Papers & Research method & Sample selection & $\begin{array}{l}\text { Research focus } \\
\text { and perspectives }\end{array}$ & Keywords & & & \\
\hline $\begin{array}{l}\text { Grzybowska and } \\
\text { Awasthi (2020) }\end{array}$ & $\sqrt{ }$ & 1991-2018 892 & $\begin{array}{l}\text { Sustainable } \\
\text { production and } \\
\text { logistics }\end{array}$ & & $\sqrt{ }$ & $\sqrt{ }$ & \\
\hline $\begin{array}{l}\text { Abdirad and } \\
\text { Krishnan (2020) }\end{array}$ & $\sqrt{ }$ & 2014-2018 56 & $\begin{array}{c}\text { Industry } 4.0 \text { in } \\
\text { supply chain } \\
\text { management }\end{array}$ & $\sqrt{ }$ & & $\sqrt{ }$ & $\sqrt{ }$ \\
\hline Jahani et al. (2021) & $\sqrt{ }$ & $2015-2020 \quad 70$ & $\begin{array}{l}\text { Industry } 4.0 \text { in } \\
\text { the procurement } \\
\text { processes of } \\
\text { supply chains }\end{array}$ & $\sqrt{ }$ & $\sqrt{ }$ & & $\sqrt{ }$ \\
\hline $\begin{array}{l}\text { Beltrami et al. } \\
\text { (2021) }\end{array}$ & $\sqrt{ }$ & 2011-2020 117 & $\begin{array}{c}\text { Industry } 4.0 \text { and } \\
\text { sustainability }\end{array}$ & $\sqrt{ }$ & $\sqrt{ }$ & & \\
\hline This paper & $\sqrt{ }$ & $2011-2020 \quad 115$ & $\begin{array}{l}\text { Sustainable logis- } \\
\text { tics enabled by } \\
\text { Industry } 4.0\end{array}$ & $\sqrt{ }$ & $\sqrt{ }$ & $\sqrt{ }$ & \\
\hline
\end{tabular}

Fig. 1 Research focus of this paper

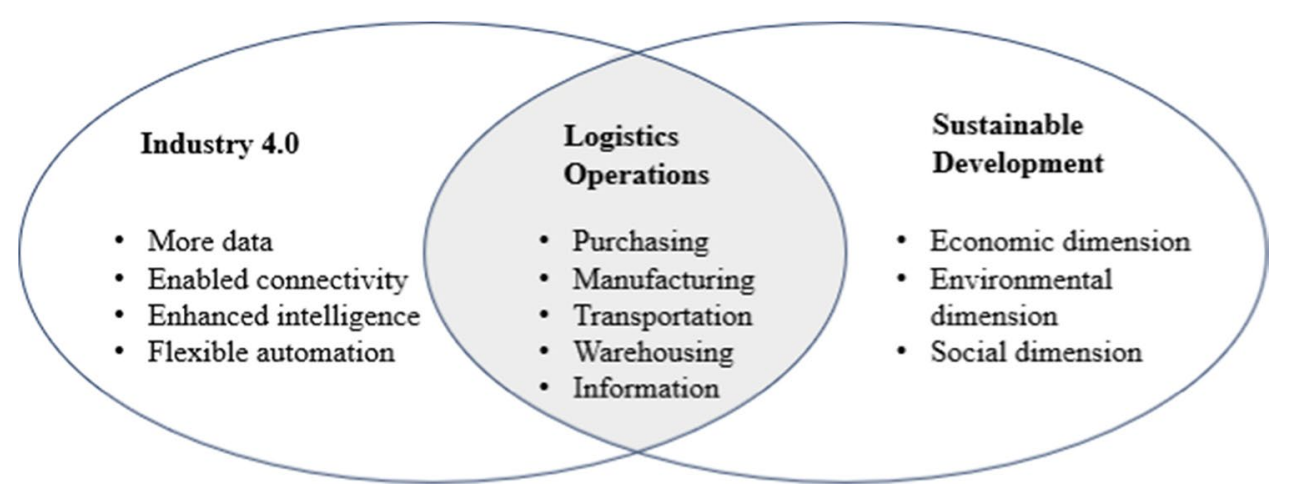

other (Larson and Halldorsson 2004). Several researchers suggest that supply chain management focuses more on forming strategies to manage the relationships and coordination among different partners (Christopher 2016, Winkelhaus and Grosse 2020), while logistics, on the other hand, emphasizes the implementation of these strategies to connect different companies with physical flows (Lummus et al. 2001). In this regard, logistics can be considered a subset of supply chain management (Winkelhaus and Grosse 2020), which focuses on the physical movement of goods and the relevant information flow.

Sustainable development has been focused on due to the concerns of increasingly severe environmental and social challenges. The widely accepted definition of sustainable development is "to meet the needs of the present without compromising the ability of future generations to meet their own needs" (Brundtland, 1987). Sustainable development is driven by three dimensions, namely, economic prosperity, environmental friendliness, and social fairness and equity, which are also known as the triple bottom line. The objective of a sustainable development society is to achieve harmony among these three dimensions. For tackling the global challenges related to hunger and poverty, health and well-being, environmental pollution, climate change, and global warming, the United Nations (UN) has recently set up 17 sustainable development goals, which are the call for actions to achieve a better future for all human beings by 2030 (UN 2015).

A drastic increase of companies has started to incorporate sustainability into logistics operations to enhance their social image and competitive advantage (Luthra and Mangla 2018). Sustainable logistics was initially focused on from the environmental perspective of lowering the ecological footprint related to logistics activities (Robert et al. 2005). The concept of green logistics was first proposed to reduce environmental impacts, e.g., GHG emissions (Dekker et al. 2012), energy consumption (Marchi and Zanoni 2017), etc., through better strategic designs and operational planning. Reverse logistics and closedloop supply chain (CLSC) have been increasingly focused to achieve sustainable value re-creation from end-of-life (EOL) products (Solvang et al. 2007) and minimizing the 
environmental pollution from waste management (Gupta 2013, Govindan et al. 2015). However, improper disposal activities lead to risk exposure to both humans and the environment (Yu et al. 2020; Yu and Solvang 2016). Thus, recent research efforts have been given to minimize the ecological footprint of both forward and reverse logistics (Yu and Solvang 2020). Furthermore, not only the economic and environmental dimensions but also the social sustainability indicators, i.e., job creation and working environments, have been holistically considered in sustainable logistics. Therefore, sustainable logistics aims at balancing the socio-economic performance of a logistics system with its eco-environmental robustness in managing system activities. This balance embodies in making decisions by considering the interplay of different logistics functions, i.e., network configuration, transportation, purchasing, demand allocation, and resource management. The optimization of a sustainable logistics system is highly dependent on the ability to balance the trade-offs among the three dimensions of sustainability.

\section{Industry 4.0}

Industry 4.0, or the fourth industrial revolution, was put forward at the Hannover Fair of Industrial Technologies in 2011 to enhance the competitiveness of the German manufacturing industry (Rojko 2017). At the global level, several countries have also launched their strategies, e.g., US National Network for Manufacturing Innovation, Japan's New Robot Strategy, and China's Made in China 2025, to strengthen their manufacturing industries by taking advantage of technological innovations (Lasi et al. 2014). While the past three industrial revolutions in history were the major results of mechanization, mass-production, and automated production (Rojko 2017), Industry 4.0 puts predominant focus on combining Internet-based communication technologies, digitalization, and future-oriented intelligent manufacturing technologies to build smart machines and systems, implement smart processes, and provide smart products and services (Lasi et al. 2014). Empowered by Industry 4.0 technologies, a smart production network can achieve real-time monitoring, responsive communications, autonomous operations, and smooth material flows. Technological advancement has provided opportunities and new business models for value creation and proposition from individualized customizations and service innovations (Esmaeilian et al. 2020). Based on previous studies (Sutawijaya and Nawangsari 2020; Strandhagen et al. 2017; Barreto et al. 2017), the 12 most important Industry 4.0 technologies are introduced as follows:

- Internet of things (IoT): IoT refers to the network interconnection that possibly connects millions of physical objects with the Internet (Xia et al. 2012). It allows different smart devices can be interconnected, monitored, communicated, and controlled based on standard communication protocols to facilitate the transition of goods, services, and information (Barreto et al. 2017).

- Cyber-physical system (CPS): CPS is the system integration of computational intelligence and physical elements, which enables effective interactions between the system and humans (Baheti and Gill 2011). CPS aims at achieving a high level of connectivity, intelligence, and automation by integrating both cyber and physical components (Zhang 2018). Thus, the level of CPS largely determines the successful implementation of Industry 4.0 (Qin et al. 2016).

- Big data analytics: Big data analytics is the state-ofthe-art analytical capability to process a large volume of dynamic data with high velocity, high complexity, and high variety. The strategies and operations of a company or a system can be continuously evaluated through massive data analytics to obtain critical insights for better business planning and decision making (Wang et al. 2016).

- Artificial intelligence (AI): AI refers to the computer systems and applications that perform tasks needing human intelligence (Pesapane et al. 2018), and it also has the capacity of learning and improving the thinking, perception, and action through training from data and algorithms (Helm et al. 2020). AI algorithms are widely used in many areas, e.g., routing, traffic management, maintenance, and security (Matlou and Abu-Mahfouz 2017).

- Cloud technologies: Cloud technologies provide a central platform for the storage and integration of configurable information technology (IT) resources, which enable the accessibility of data and resources from decentralized locations. Cloud technologies form the service-oriented architecture that links the concepts of Platform-as-a-Service (PaaS), Software-as-a-Service (SaaS), and Information-as-a-Service (IaaS) (Benotmane et al. 2017).

- Blockchain: Blockchain is an innovative way for implementing distributed ledger technologies that can be programmed to record and track any data by anyone without a central authority, and it is a peer-to-peer network and a nondestructive way to track data changes over time (Esmaeilian et al. 2020).

- Autonomous robots: Autonomous robots are highly intelligent and capable of self-organization, self-evaluation, and decision-making for executing several tasks without human instructions (Bekey, 2005). An autonomous robot can be in various sizes and shapes, and with different levels of autonomy, mobility, and intelligence (Bekey, 2005). 
- Unmanned aerial vehicle (UAV): UAV, or commonly referred to as the drone, is a flying device that does not require a human pilot onboard. It is typically piloted by remote control or by a combined control with computer programming (Yang et al. 2020).

- Additive manufacturing (AM): $\mathrm{AM}$, or 3D printing, is a layer-wised production or generative manufacturing. By adding material layer upon layer, it provides opportunities for the accurate production of items at the required size, shape, and material without any wastes (IsasiSanchez et al. 2020). With technological maturity and the growing awareness of sustainability, AM has been increasingly used as the main element in both production and logistics processes.

- Augmented reality $(A R)$ : AR in the overlaying of computer-generated digital information, e.g., texts, images, and effects, in the real world, which can interact with users and give real-time instructions in a user-friendly way (Anurag 2020).

- Virtual technologies and simulation: Virtual technologies are powerful tools, which can mimic, evaluate, optimize, and control a real-world entity or a system in its digital representation under a risk-free and cost-efficient environment.

- Cybersecurity: Cybersecurity refers to the protection and defense of critical data, servers and computers, software, and other IT resources from cyber-attacks (Craigen et al. 2014).

\section{Research method}

A systematic literature review aims at identifying, evaluating, interpreting, and categorizing all relevant articles engaging one or more research questions and topics (Kitchenham 2004, Ranieri et al. 2018). Compared with a narrative literature study whose results mainly focus on the descriptive findings of a specific domain of knowledge and may suffer from selection bias, a systematic literature review can present a comprehensive overview of the research landscapes (Evangelista and Durst 2015). Based on Kazemi et al. (2019) and Ren et al. (2020), a systematic literature review consists of the following steps:

(1) Identification of research questions: Formulating the research questions to be answered.

(2) Literature search and selection: Developing a document search strategy with a broad combination of keywords to have a comprehensive overview of the area under investigation. Then, proper filters are set up so that the most relevant sample of articles is solicited.

(3) Bibliometric analysis: Presenting a quantitative analysis and data visualization of the selected sample of articles to understand the key characteristics of the topic, e.g., publication trend, journals and citations, collaborations, and keyword focus.

(4) Content analysis: Performing a detailed content analysis of the selected articles to summarize the contributions of several related topical areas. Based on this, the current research landscape can be understood, and future research opportunities can be identified.

The research questions are formulated to reflect the aim and scope. This paper links two concepts: sustainable logistics and Industry 4.0, and their interactions in literature are thus focused on. Concerning these concepts, the following three research questions are proposed to understand the state of knowledge of adopting Industry 4.0 technologies in sustainable logistics:

- RQ1: What literatures exist on sustainable logistics enabled by Industry 4.0 and how can they be categorized?

- RQ2: What are the implications of sustainable logistics in the Industry 4.0 era?

- RQ3: What are the future research directions to fill the gaps?

Based on the research questions above, Fig. 2 formulates the document search strategy, which includes five steps: (1) keyword search, (2) setting of the filters, (3) investigation of the titles and abstracts, (4) investigation of the full text, and (5) result analysis, respectively.

1. Keyword search: In this paper, we performed a keyword search using two electronic databases: Scopus and Web of Science core collection. The literature search was conducted in November 2020, and two main sets of keywords related to sustainable logistics and Industry 4.0 were used. The first set of keywords is associated with sustainable and smart logistics, which consist of "sustainable logistics," "smart logistics," and "logistics 4.0". Besides, since many logistics issues were discussed in the context of supply chains, "sustainable supply chain" was added to this group. The other set of keywords related to Industry 4.0 includes "Industry 4.0," "I4.0," "smart manufacturing," "smart production," "the fourth industrial revolution," "IoT," "CPS," "big data analytics," "augmented reality," "cloud computing," "additive manufacturing," "autonomous robots," "smart robot," "simulation," "cybersecurity," "virtual technology," "artificial intelligence," "unmanned aerial vehicle," and "blockchain". The Boolean operator "OR" was used to combine the keywords within the same group, and "AND" was used to combine the two main groups of keywords related to both sustainable logistics and Industry 4.0. The initial 


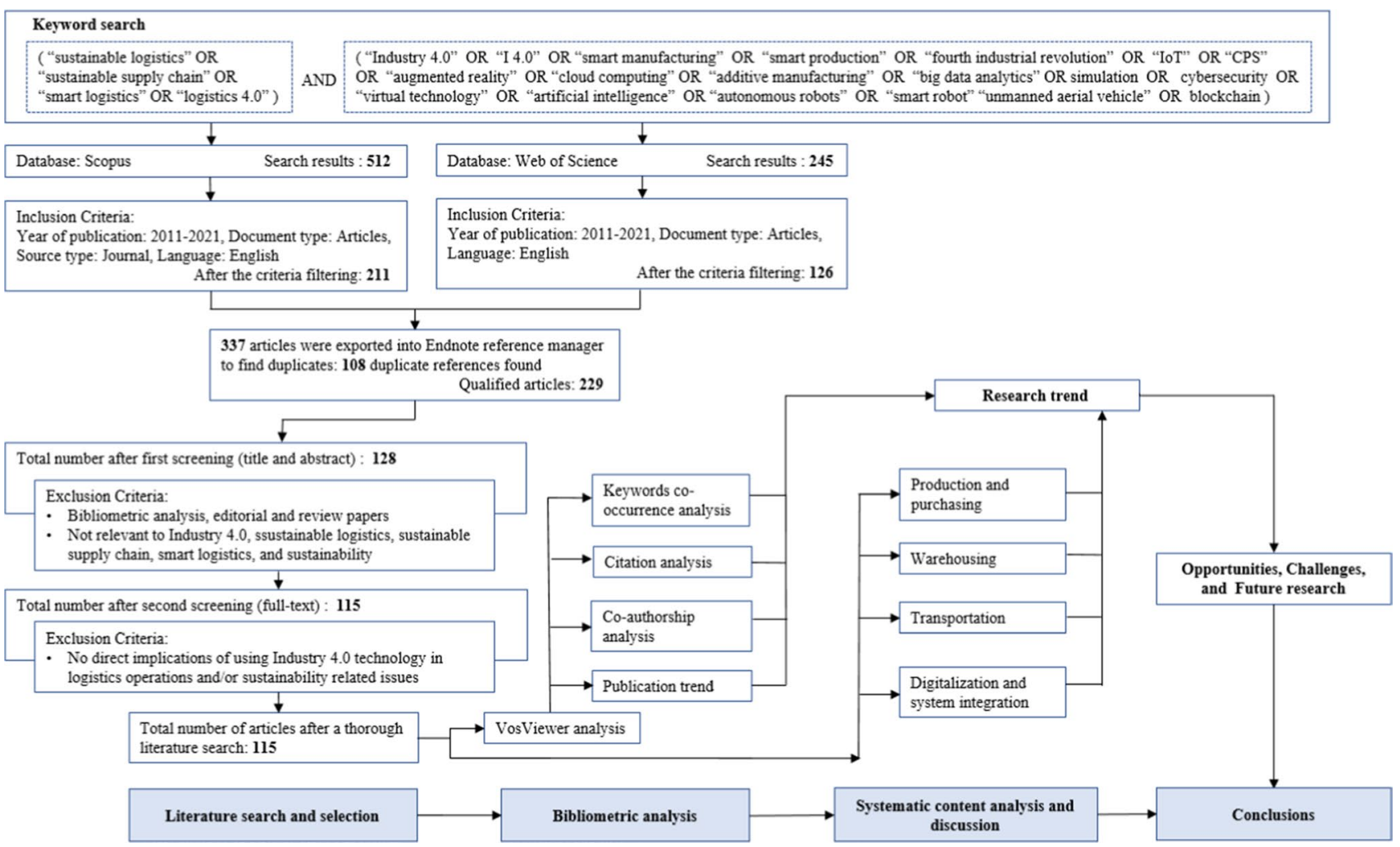

Fig. 2 Research method

search yielded 512 results in Scopus and 245 in Web of Science.

2. The setting of the filters: The second step is to set up several filters to select the most relevant articles, and the papers are excluded if they are not within the research scope or are irrelevant for answering the research questions. First, since the concept of Industry 4.0 was originally presented at the Hannover fair in 2011 (Rojko 2017), the search horizon was re-set to 2011-present. Considering the quality and rigor of selected papers, the search results were also limited to journal articles that had passed the peer-review stage. The publishing language was restricted to English. Thus, conference proceedings, book chapters, pre-prints, and papers published in another language were excluded in this study. After implementing these new filters, the search resulted in 211 and 126 qualified articles in Scopus and Web of Science, respectively. We combined the search results from the two databases and removed the duplicated ones, which resulted in 229 articles.

3. Investigation of the titles and abstracts: First, we investigated the type of paper in the filtered sample, 8 bibliometric analysis papers; editorial and review articles were excluded. Then, we investigated the thematic relevance of these articles; papers that have little relevance of using Industry 4.0 and smart technologies in sustainable logistics were excluded. Besides, papers dealing with behavior supply chain issues, e.g., customer relations management, but without a logistics focus, were also excluded. In total, 101 papers were excluded in this stage.

4. Investigation of the full text: In the next step, we conducted a full-text reading in the second-round paper selection. In this stage, special emphasis was paid to the papers that lack direct implications for the proposed research questions. Even though these papers have both keywords of Industry 4.0 and logistics or sustainability, the application of Industry 4.0 technologies in sustainable logistics is not thoroughly discussed, so these papers are considered irrelevant to answer the research questions. In this stage, another 13 papers were considered not to fit well with the topic and were thus removed. Then, a total of 115 papers were selected.

5. Result analysis: Based on the selected sample, the bibliometric analysis was conducted to provide the results of publication trend, source distribution, co-authorship analysis, citation analysis, and keyword co-occurrence analysis. Next, the content analysis was performed to discuss how different logistics operations can be 
improved by Industry 4.0 technologies and present the opportunities, challenges, and future research directions.

\section{Bibliometric analysis}

\section{Publication trend}

Figure 3 illustrates the number of articles published between 2012 and 2020 . It can be seen that increasing focuses have been given to adopting Industry 4.0 technologies in sustainable logistics planning and operations, and this trend has experienced a significant acceleration since 2017. In 2020 alone, 48 papers have been published in international journals, which amounts to $41.7 \%$ of the total publications in the last decade. The publication trend shows that the recent rise of Industry 4.0 related research has presented new opportunities for achieving sustainable value creation, environmental friendliness, and improved social responsibility in logistics activities, which have been noted by both industry professionals and academia.

\section{Source distribution, influences, and interactions}

Table 2 presents the source distribution of the selected 115 articles, which are published in 73 journals. The most popular 15 journals in this field published 57 articles, accounting for nearly $50 \%$ of the total amount. With 9 papers published, the Journal of Cleaner Production has the highest number of publications, and it is followed by Sustainability with 8 papers. Both are multidisciplinary with the primary focus
Fig. 3 Publication trend of sustainable logistics enabled by Industry 4.0

Table 2 Source distribution

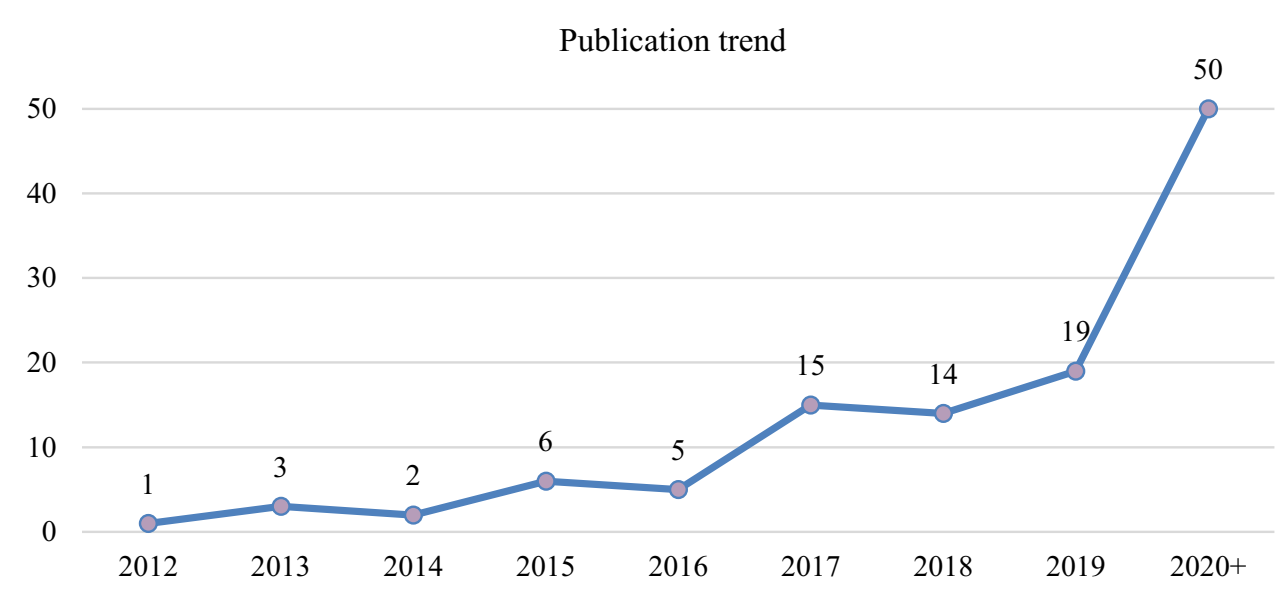

Publication source (Journal)

Num-

ber of papers

Journal of Cleaner Production

9

Sustainability Switzerland

8

International Journal of Production Research

7

Resources Conservation and Recycling

5

IEEE Access

5

Industrial Management and Data Systems

3

International Journal of Production Economics

3

Journal of Self Governance and Management Economics 3

Applied Sciences Switzerland

2

Chemical Engineering Transactions

2

Computers and Electronics in Agriculture

2

Economics Management and Financial Markets 2

International Journal of Logistics Management 2

International Journal of Logistics Research and Applications 2

Transportation Research Part E Logistics and Transportation Review 2

Others (1 per journal) 58 
on theoretical advancements and practices in sustainable development and circular economy. The next three most popular journals are the International Journal of Production Research, Resources Conservation and Recycling, and IEEE Access, contributing to 7, 5, and 5 papers, respectively. Followed by Industrial Management and Data Systems, International Journal of Production Economics, and Journal of Self Governance and Management Economics with 3 articles each. Among the most popular 15 journals, Sustainability, IEEE Access, and Applied Sciences are open access journals, while the others are hybrid journals with both subscriptions only and paid open access options. These 15 journals cover various topics, i.e., sustainable development, production and economics, engineering, computer and data sciences, and logistics and transportation, which shows the cross-disciplinary nature of combining Industry 4.0 and sustainable logistics.

We conducted a co-citation analysis to understand the interactions among the most influential journals in this field. The minimum number of citations per journal was set to 20 in VOSviewer, which led to 16 qualified sources for the co-citation analysis. Compared with the list of journals in Table 2, six new journals were selected namely Computers \& Industrial Engineering, Expert Systems and Applications, Omega, Journal of Operations Management, International Journal of Physical Distribution \& Logistics Management, and Procedia CIRP. The result is shown in Fig. 4. The size of each node shows the number of citations received by the relevant papers published in each journal, and the arc linking two journals illustrates the co-citation strength between them.

Three general clusters of journals are identified based on their co-citation activities. The first cluster focuses on operations research and operations management. Besides, two inter-disciplinary journals (Sustainability and IEEE Access) are also assigned to this cluster. The second cluster relates to production technologies and management, while the third cluster emphasizes industrial applications. The journals in the second cluster, particularly the Journal of Cleaner Production, International Journal of Production Economics, and International Journal of Production Research, have yielded the most significant impact and the most active interactions with others in the contemporary research associated with sustainable logistics and Industry 4.0. In addition, the active interactions between clusters 1 and 2, and between clusters 2 and 3 indicate that production-related journals become a bridge to connect the theoretically focused operations research and management methods with real-world industrial applications.

\section{Influential research, co-authorship network, and co-citation map}

Table 3 presents the authors, technologies, applications, and the number of citations of the top ten most influential papers by the time of this research. The most cited article is given by Saberi et al. (2019) in which the relationship between blockchain and sustainable logistics is thoroughly investigated. Followed by Barreto et al. (2017) and Luthra and Mangla (2018), the implications and challenges of Industry 4.0 on logistics activities are discussed. The fourth and fifth highly cited papers are from Prause (2015) and Prause and Atari (2017), which focus on Industry 4.0 enabled architectures of sustainable business models and sustainable manufacturing networks related to logistics operations. In addition, the other papers give comprehensive discussions on the use of several emerging technologies to achieve smart and sustainable logistics, i.e., cloud-enabled product-service system (Zhang et al. 2016), IoT-based smart warehouse management (Lee et al. 2018; Trappey et al. 2017), smart technology-enabled innovative and sustainable business models (Strandhagen et al. 2017), smart decision-making of

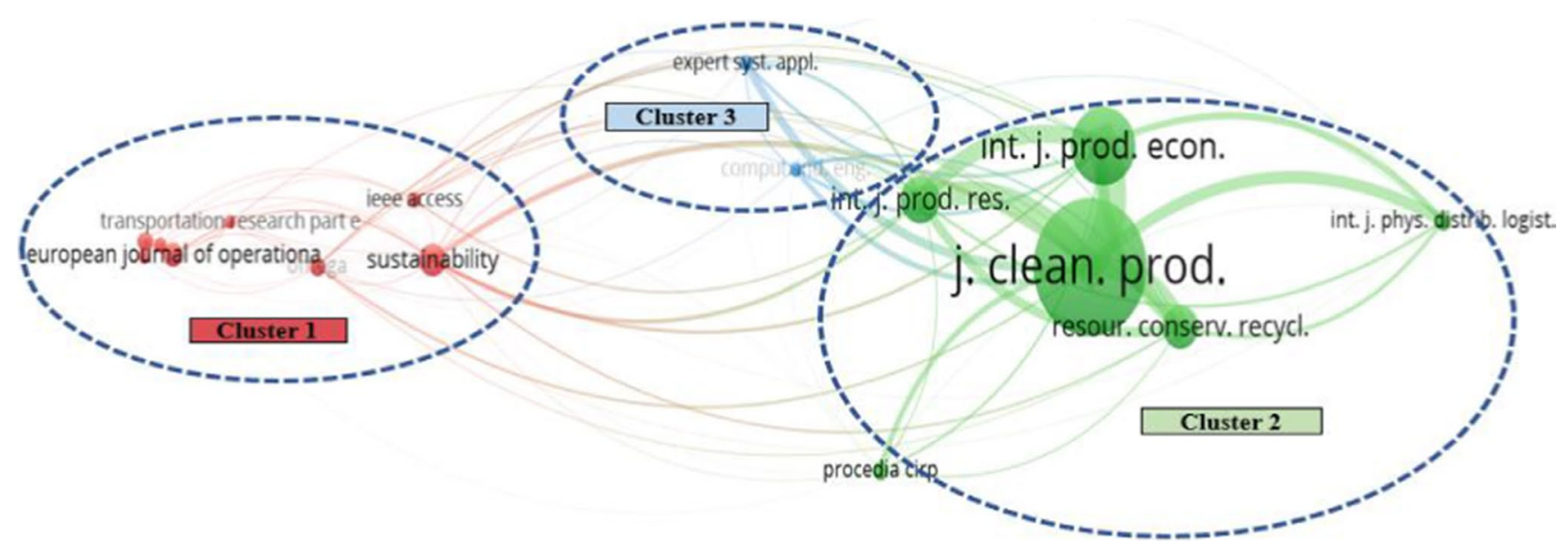

Fig. 4 The journal co-citation network 
Table 3 The top 10 highly cited articles

\begin{tabular}{|c|c|c|c|}
\hline Papers & Technological keywords & Application focuses & Citations \\
\hline Saberi et al. (2019) & Blockchain & Sustainable logistics and supply chain & 225 \\
\hline Barreto et al. (2017) & Industry 4.0 & Logistics operations & 132 \\
\hline Luthra and Mangla (2018) & Industry 4.0 & $\begin{array}{l}\text { Sustainable logistics and supply chain challenges in devel- } \\
\text { oping countries }\end{array}$ & 106 \\
\hline Prause (2015) & Industry 4.0 & Sustainable business models & 60 \\
\hline Prause and Atari (2017) & Industry 4.0 & Sustainable production networks and logistics & 52 \\
\hline Zhang et al. (2016) & Cloud technology & Product-service oriented cloud logistics & 52 \\
\hline Lee et al. (2018) & IoT & Smart warehouse management & 47 \\
\hline Strandhagen et al. (2017) & Industry 4.0 & Sustainable business innovations for Logistics 4.0 & 43 \\
\hline Cole et al. (2019) & Blockchain & Logistics and supply chain & 40 \\
\hline Li et al. (2019) & Cloud technology & Sustainable logistics and supply chain & 34 \\
\hline
\end{tabular}

sustainable logistics (Li et al. 2019), and sustainable logistics practices (Longo, 2012, Hilpert et al. 2013). The results show that, in sustainable logistics systems, the application of several Industry 4.0 technologies, i.e., blockchain, IoT, and cloud-based technologies, has enjoyed tremendous popularity among recent research.

To identify the most fruitful collaborations and active interactions among different researchers in this field, coauthorship mapping and co-citation mapping are given in Figs. 5 and 6. With the help of VOSviewer, a comprehensive co-authorship network analysis of 363 authors was performed, whose result illustrated the 16 most collaborative authors and their collaborations on the time horizon. The nodes are identified by the authors' names, whose sizes show the levels of collaborations of different authors. The arcs link these authors with the number of co-authored papers and the time of publications, which are represented by the width and the color of an arc. The total link strength (TLS) of an author is determined by both the number of connecting links and the number of co-authored documents. As shown in Fig. 5,

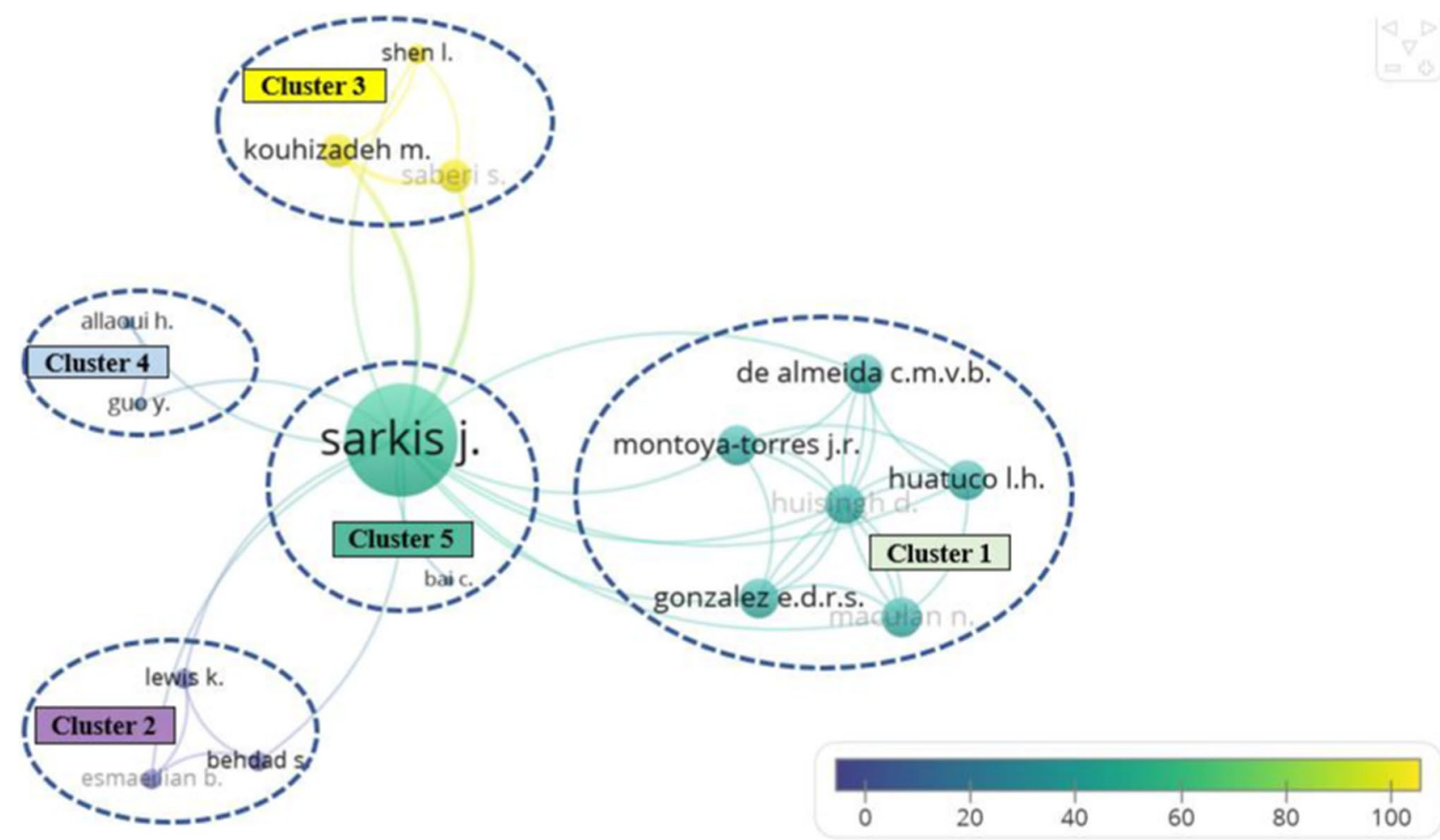

Fig. 5 Co-authorship mapping of collaboration 


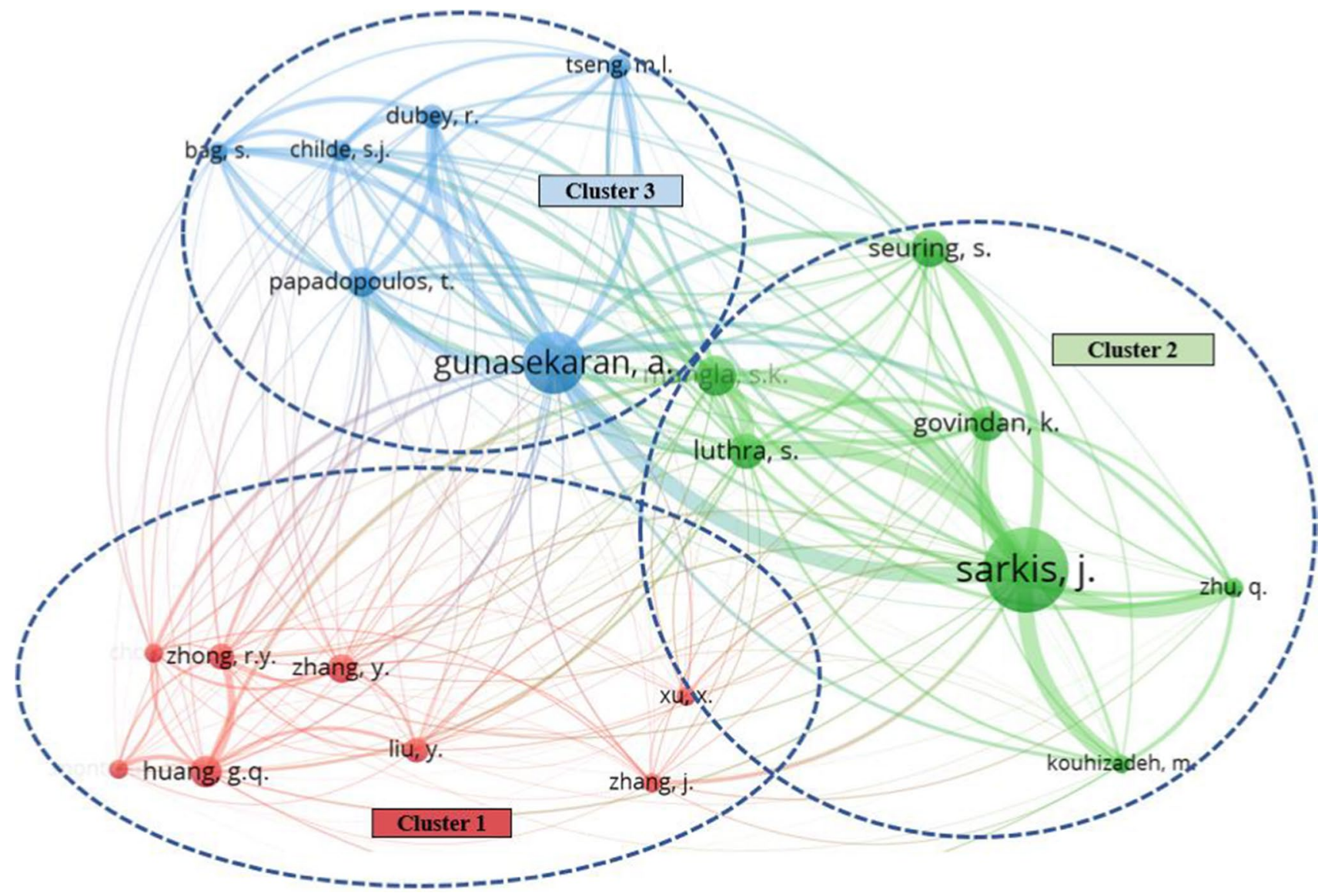

Fig. 6 Co-citation map

these 16 authors are divided into five clusters with a different number of co-authored papers and citations. The co-citation map in Fig. 6 evaluates the influence of the key researchers and the impacts of their papers on other researchers' works in sustainable logistics enabled by Industry 4.0. In this analysis, the minimum number of citations per author was set to 20 to identify the most influential researchers who drove the advancement of this field. The results have shown the 21 most influential researchers and their co-citation networks.

Through the comparison between the co-authorship map and the co-citation map, two interesting findings are obtained. First, even though the combination between sustainable logistics and Industry 4.0 has been extensively focused on by worldwide researchers, the collaboration network has not become extensive compared with other well-established fields. This is because this emerging and cross-disciplinary research topic is still at its initial stage. Another reason may be explained by the time from cooperation to publication is usually very long, which may also significantly affect the results of the co-authorship analysis. The second finding is that, even if the collaboration potential has not been fully exploited, several influential researchers and works have led the research and drastically push forward the knowledge accumulation, which forms the foundation to promote fruitful collaboration in the future.

\section{Research highlights and keywords}

To identify the research highlights, a co-occurrence analysis of the highly used keywords related to Industry 4.0 and sustainable logistics was performed. For presenting a complete overview of the current research landscape, we used "all keywords" and "full counting" options to enumerate all the keywords that appeared in previous studies and calculate the total co-occurrence. With the minimum threshold of three times of co-occurrence, Fig. 7 shows the mapping and interactions of the 78 qualified ones out of the total 1006 keywords. The clusters, occurrences, and TLSs of these keywords are given in Appendix 1 (Table 4).

The 10 mostly used keywords in the selected literatures consist of supply chain management (Occurrence $=39$, $\mathrm{TSL}=264)$, Industry $4.0($ Occurrence $=34, \mathrm{TSL}=151)$, 


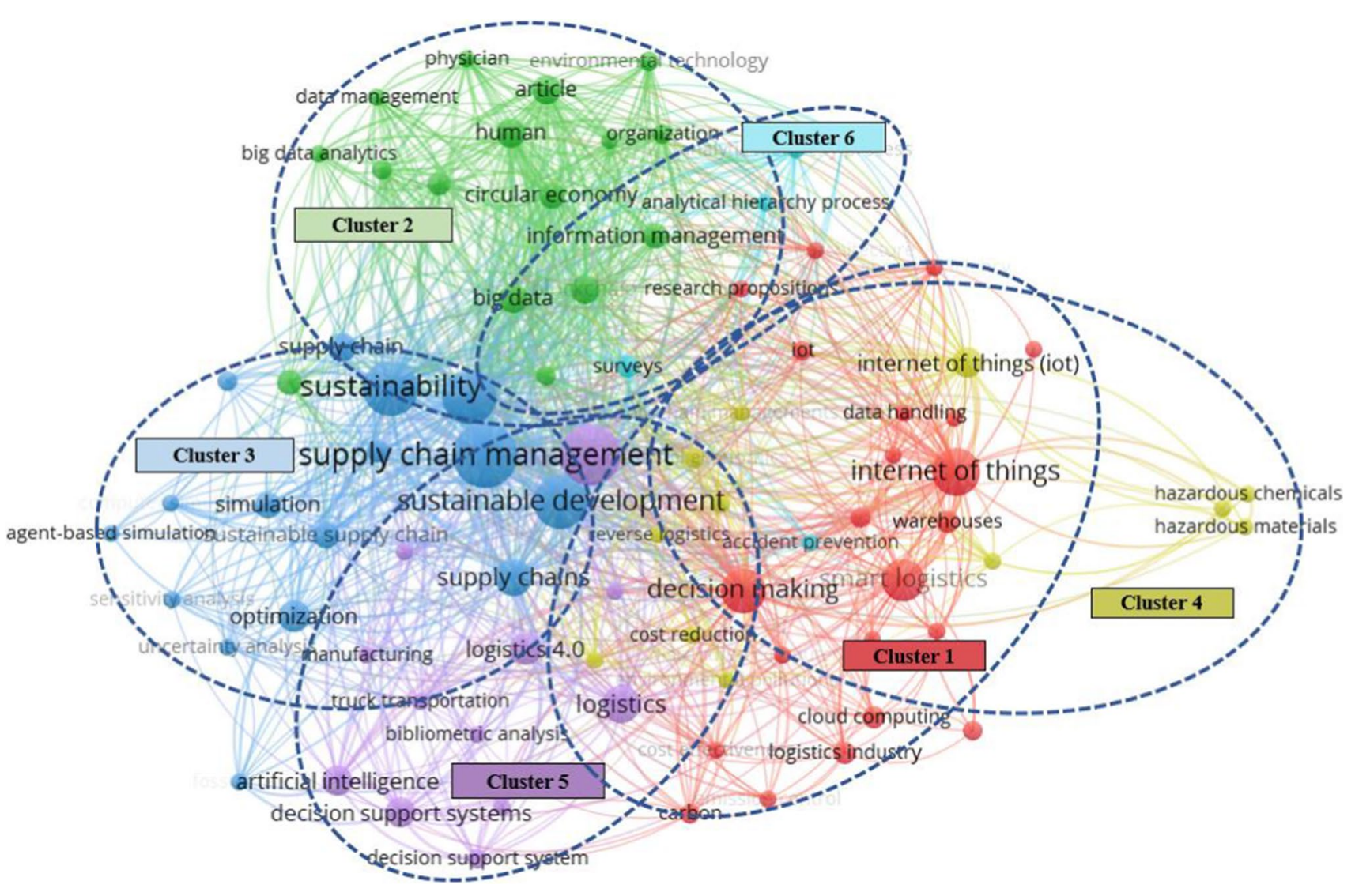

Fig. 7 Keyword co-occurrence map

sustainability (Occurrence $=29$, TSL $=191$ ), sustainable development $($ Occurrence $=28$, TSL $=220)$, sustainable supply chains (Occurrence $=28$, TSL $=235$ ), internet of things (Occurrence $=21$, TSL $=117$ ), decision making (Occurrence $=19, \mathrm{TSL}=115)$, smart logistics $($ Occurrence $=17$, $\mathrm{TSL}=52)$, logistics (Occurrence $=14, \mathrm{TSL}=59$ ), and supply chains (Occurrence $=13$, TSL $=94$ ). Clearly, these mostly used keywords have critical impact and define the general nature of smart and sustainable logistics systems. Besides, it is noted that even if supply chain management and logistics are two concepts, they are not mutually exclusive. Since logistics is considered an important element of supply chain, many relevant studies discuss the sustainable logistics enabled by Industry 4.0 in the context of supply chain management and sustainable supply chain.

The 78 frequently appeared keywords are grouped into six clusters, with which the mainstream research directions on Industry 4.0 enabled sustainable logistics can be pinpointed. The six keyword clusters have identified the different research focuses. Cluster 1 comprises 23 keywords focusing mainly on the application of new technologies, e.g., IoT, cloud computing, etc., in smart warehousing, smart information systems, and other logistics operations. Cluster 2 contains 16 items that predominantly emphasize the use of big data analytics and blockchain to improve sustainable logistics and circular economy. Cluster 3 covers 16 nodes focusing on sustainable logistics operations with optimization and simulation methods. Cluster 4 consists of 11 keywords, which engage in the economic, environmental, and social sustainability of hazardous material management. Cluster 5 includes 8 nodes that focus on improved decisionmaking with AI and other smart technologies. Cluster 6 consists of 4 keywords related to literature studies, which show efforts have been spent to summarize the recent research results.

\section{Content analysis}

The keyword co-occurrence analysis has shown the importance of technology and data in sustainable logistics, and the content analysis is performed to understand how smart technologies and data analytics will affect the paradigm of logistics operations and the system's sustainability. Content analysis is an important step to systematically analyze the research development of several topical areas (Kazemi et al. 2019). In this section, we present a detailed content analysis of four main topics related to sustainable logistics 
operations throughout the pre-production, in-production, and post-production stages. First, smart production drives new demand patterns and changes the way of how demands are satisfied, and it consequently changes the demands of purchasing and logistics services. Thus, Industry 4.0 enabled sustainable production and purchasing was first discussed. The smart solutions for the two most important logistics operations, namely, warehousing and transportation, were then introduced. Last but not least, the general digitalization and system integration issues for streamlining different operations within a sustainable logistics system were given. Figure 8 shows the article distribution over the four topics, and it is noted $22.6 \%$ of papers focus on two or more topical areas. A summary of relevant papers, technologies, and sustainability dimensions (environmental or social) of logistics systems in each topic is given in Appendixes 2, 3, 4, and 5 (Tables 5, 6, 7, and 8).

\section{Industry 4.0 enabled sustainable production and purchasing}

In an increasingly globalized and dynamic market, Industry 4.0 technologies play vital roles in improving the sustainability of production operations, purchasing decisions, and resource planning. These technologies can enable efficient commodity flow and information flow from raw material purchasing to product delivery through an open, dynamic, smart, and sustainable production-logistics network (Prause and Atari 2017). Besides, they can affect the capabilities of dynamic remanufacturing, green production, waste reduction, and recycling in a sustainable logistics system (Gonzalez et al. 2015; Björklund and Forslund 2018).

IoT and autonomous robots are the fundamental parts of a smart production system, which allow for a high level of connectivity and automation. IoT-embedded systems can provide better tracking and traceability, which help products move faster and provide customers with real-time information about the deliveries (Bag et al. 2020c). The integration of IoT-enabled devices, autonomous robots, cloud-based data analytics form a connected, digitalized, and smart production CPS. This smart networking of both physical devices and cyber intelligence enables effective machine-to-machine communications and human-machine interactions (Esmaeilian et al. 2020), which pave the way for an autonomous production system with high flexibility and agility.

Big data analysis has gained increasing focus in production and logistics. Advanced analytical tools, i.e., AI and machine learning, have been used to treat a large amount of complex data collected from different sources (Wang et al. 2016). The results can be used to analyze market trends, purchasing patterns, potential risks, equipment maintenance cycles (Samir et al. 2019), delivery reliability and responsiveness (Bag et al. 2020c), and other important performance indicators (Wang et al. 2016), based on which production activities can be planned more sustainably.

AM can be used for on-demand and decentralized production, which allows customers to be actively involved in product design. AM can help to reduce size-related resource constraints (Beltagui et al. 2020), to minimize waste of materials, and to support low-volume and highly customized production, e.g., spare parts (Isasi-Sanchez et al. 2020). The open design architecture of AM facilitates market growth, promotes localized production, generates value-differentiated consumer demands, changes the market leaders' practices, and supports and diffuses social sustainability in their daily activities (Beltagui et al. 2020).

Cloud technologies provide a platform for centralized storage and decentralized access of various data analytics
Fig. 8 Article distribution over different topical areas

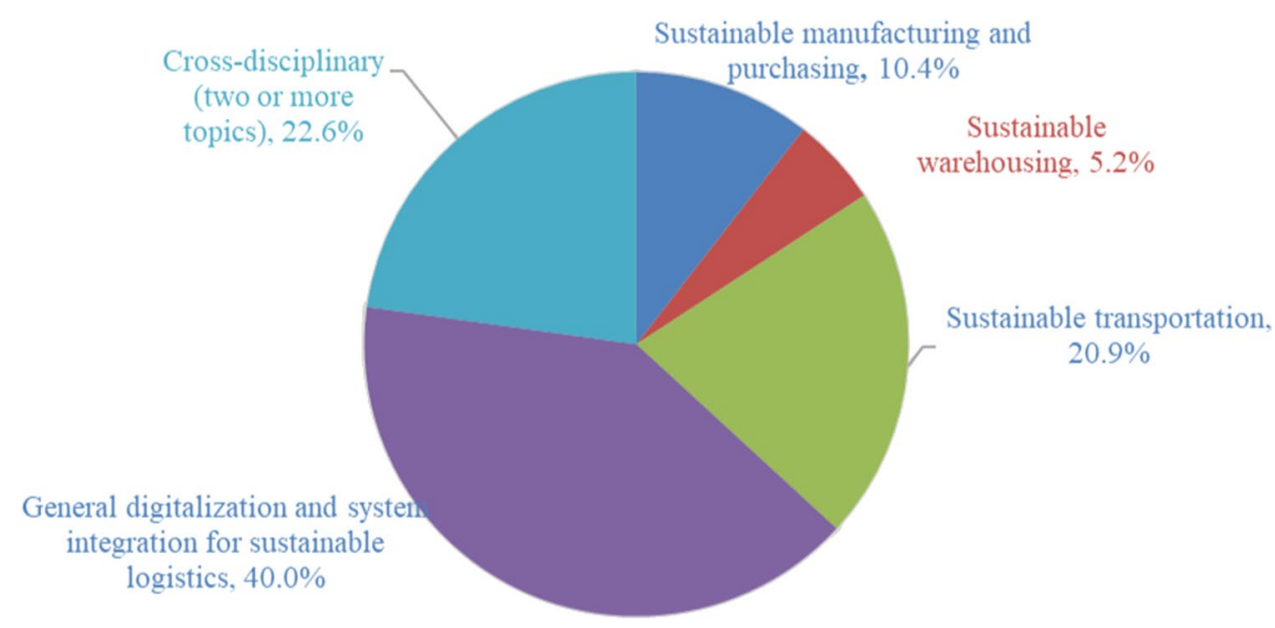


and computing tools to fulfill the growing demands of mass individualization, improve the responsiveness to customers and market change, and enable broader global cooperation (Strandhagen et al. 2017). The maturity of supplier selection and purchasing strategy can be affected by the effectiveness and timeliness of data exchange with partners (Facchini et al. 2020). In this regard, Ma et al. (2017) presented a sustainable make-to-order apparel supply chain model with a collaborative cloud service platform. The key information, i.e., the order queue of the supplier, the raw material status, and the production capacity can be accessed in real-time, which are used for making sustainable production and purchasing decisions in the apparel industry.

With the high reliability and transparency, blockchain is another highly focused Industry 4.0 technology for the effective integration of information flow and material flow (Saberi et al. 2019). Blockchain can change the way of obtaining, managing, and using the critical product data through the entire product lifecycle, which enables a better product design, more effective production and sales planning, and responsible recovery at the EOL stage (Esmaeilian et al. 2020). From the environmental perspective, blockchain can help to reduce waste and promote recycling. In addition, blockchain traceability can improve social sustainability through a better assurance of human rights, equity, and safety aspects (Saberi et al. 2019). For example, the traceable record of product history allows buyers and producers to trade with high confidence.

\section{Industry 4.0 enabled sustainable warehousing}

Warehouses are the important storage and hub facilities in a logistics network, which provide protection of goods and bridge the gap between different logistics activities, e.g., purchasing and production. Warehouse management consists of four operations, namely, receiving and recording of goods from different suppliers, storing goods at appropriate locations, retrieving and picking goods when they are needed, and shipment to customers (Ten Hompel and Schmidt 2008). Industry 4.0 technologies have brought opportunities for smart and sustainable warehousing solutions with enhanced capability of information and communication-based decision making (Trab et al. 2017). The use of IoT, CPS, AI, and autonomous robots has been investigated in various operations (Lee et al. 2018), e.g., product receiving, identification, storing and allocation (Zhou et al. 2017), and product picking (Rakyta et al. 2016) and shipping with autonomous robots (Trab et al. 2017; Yavas and Ozkan-Ozen 2020).

IoT-enabled devices have been widely used in smart warehouse management by several large companies, i.e., DHL, Amazon, and JD.com. The combination of both IoT and CPS provides a quick interconnection of smart assets in a warehouse, e.g., pallets, forklifts, machines, and robots. This enables real-time data collection and system monitoring of goods, equipment, and personnel, which improves warehousing operations, decision making, safety, and resource utilization (Jabbar et al. 2018; Tang et al. 2020). Besides, by using IoT, cloud technologies, and blockchain (Shoaib et al. 2020), traceability and transparency can be facilitated, and the errors and delays of warehousing operations can be minimized (Lee et al. 2018).

Combining cloud-based data collection, analytics, and optimization enables better communication and positioning of transport vehicles and more accurate prediction of their arrival time in order to optimize the docking slot and achieve just-in-sequence delivery (Barreto et al. 2017; Ding et al. 2020), through which good handing costs, greenhouse gas (GHG) emissions, and truck drivers' working hours can be reduced. Lv et al. (2020) investigated a data-driven optimization framework for improving the operational efficiency of yard management in steel logistics parks. With the help of smart sensors, AI-supported optimization can adjust the allocations and e-routes of goods and optimize the work assignments with real-time information of available spaces and resources (Munsamy et al. 2020). Besides, these technologies can provide better visibility of inventory levels, enhanced inventory accuracy and space usage (Lee et al. 2018), reduced inventory costs, improved process management and safety (Trab et al. 2017), and better customer services.

Smart robots consist of various sensors and powerful processors that allow them to sense extensively, decide intelligently, and behave precisely (Liu et al. 2018). Smart robots have been increasingly used to replace manual operations, minimize errors, and improve effectiveness and safety. The use of UAVs for picking, data collection, and process monitoring has also been discussed (Gunal, 2019). AM is another emerging technology that has been increasingly used in warehouse management, and it provides an inexpensive solution for holding digital inventory of a large variety of products with low and irregular demands.

Virtual technologies have been extensively adopted to improve the effectiveness and training of warehousing operations. For instance, virtual reality (VR) can be used for the training of new employees without interrupting warehouse operations (Liu et al. 2018), and under minimum risks, it can also be used for providing the training of some dangerous operations, e.g., hazardous materials handling. Simulation has been widely used for visualization, testing, and performance evaluation of new technologies and processes (Azarian et al. 2019). Several logistics companies, e.g., DHL, use AR to manage and control the warehousing processes (Yavas and Ozkan-Ozen 2020), where real-time 
instructions and task visualizations can be given to the operators in order to provide better assistance and maximize their effectiveness.

\section{Industry 4.0 enabled sustainable transportation}

The transportation of goods among different locations largely determines the sustainability of a logistics system, and Industry 4.0 technologies can be used for improving sustainability in different transportation activities (Sun et al. 2020), e.g., intelligent transportation systems (Wen et al. 2018), vehicle routing, emission reduction (Pan et al. 2020), green-fleet management (Samir et al. 2019), and pick-up and delivery services (Frontoni et al. 2020). The integration of IoT and AI into a cloud-based platform enables real-time data processing and analysis of traffic conditions, vehicle information, dynamic demands, and recourse availability and usage. Combining advanced optimization algorithms, e.g., genetic algorithm and simulated annealing algorithm (Zhang, 2018), the real-time information can be used for better transportation planning and timely decision making to minimize transport delays (Zhao et al. 2020), increase accident responses, reduce fuel consumption and costs, and minimize GHG emissions, noise (Wen et al. 2018) and the population exposure to risks and hazards (Anandhi et al. 2019).

Big data analytics and AI provide computational powers for processing a large amount of multi-sourced data collected from IoT sensors and selecting the right quality and quantity of data for different decision-support tools, and this has led to an increasing focus on data-driven sustainable transportation planning and logistics optimization. $\mathrm{Su}$ and Fan (2020) investigated a green vehicle routing system embedded with big data analytics and AI for better transportation of a smart logistics system, where the performances of costs, energy consumption, GHG emissions, and customer services were improved. Data-driven optimization has also been used in the sustainable planning of multimodal transportation (Sun et al. 2018). Through the data-driven capacity balancing and optimization of different transportation modes, the use of low-carbon and environmentally friendly transportation modes has been drastically increased, e.g., a shift from road to rail transport (Dong and Boute 2020), without a significant compromise on cost-effectiveness.

Virtual technologies provide powerful modules to include sustainability in the modeling and analysis of real-world logistics systems (Hoffa-Dabrowska and Grzybowska 2020). Sun et al. (2018) presented a simulation-based analysis for the planning, decision making, and control of a CPS-enabled logistics network. By minimizing the number of trucks with low or empty loads, the simulation improves transportation strategies with reduced fuel consumption, costs, GHG emissions, and truck drivers' working hours. Simulation models have also been used to show the benefits of resource sharing in sustainable logistics systems (Hoffa-Dabrowska and Grzybowska, 2020). Besides, combined optimization and simulation have been increasingly used in sustainable logistics, e.g., infrastructure design (da Silva et al. 2017) and network optimization (Hong et al. 2019), to take advantage of the strengths of both methods.

Industry 4.0 technologies have changed the ways of goods delivery. The focus on smart and self-driving vehicles, i.e., autonomous trucks and lorries, has shown the potential to reduce the costs, accident rates, and $\mathrm{CO} 2$ emissions (Gružauskas et al. 2018). Another game-changing technology is the UAV, which has been used in many countries for the delivery of parcels, foods, medicines, vaccines, and blood samples (Yang et al. 2020). The UAV or combined vehicle-and-drone system becomes appealing for highly agile last-mile delivery services, which has been practiced by several large companies, e.g., Amazon and Walmart (Issaoui et al. 2020). Besides, it also provides a cost-effective solution for the delivery of low-quantity and emergency goods, e.g., medical supplies, to remote areas (Tatham et al. 2017).

Blockchain-based platforms have been used for helping companies track and measure carbon emissions related to their logistics activities (Saberi et al. 2019). Deep learning and AI technologies have shown the value of using digital voice assistance and intelligent information support system in transportation and logistics services, which improve the deliverymen's working experiences, service levels, and operational efficiency (Hsiao and Chang 2019).

\section{Digitalization and system integration for sustainable logistics}

In general, digitalization is the most important characteristic of an Industry 4.0 enabled logistics system, which aims at the transformation toward fully data-driven operations (Krykavskyy et al. 2019). This digital transformation requires a high-level integration of different smart technologies and systems, which will promote operational excellence and create sustainable value-added opportunities (Ebinger and Omondi 2020). In this regard, many studies have been conducted for enhancing the digitalization and system integration of the entire logistics system.

Many believe IoT-based platforms, which establish the connection between the physical world and the digital world (Tang et al. 2020), are the initial step to achieve a high-level digitalization and system integration of different logistics operations. Big data analytics and AI are digital elements for trend analysis, facility control, risk management, and other logistics operations (Bag et al. 2020b). The cloud-based integration of IoT and AI enables real-time data analytics and optimal decision support. Besides, advanced controlling and 
autonomous technologies improve the operational efficiency, accuracy, and safety of various logistics activities. Trappey et al. (2017) investigated an IoT- and AI-enabled intelligent logistics system, which improved logistics services by integrating several operations, i.e., machine-loading control, production flow monitoring, vehicle routing, delivery schedules, and vehicle movement tracking.

The multi-sourced real-time information flow not only improves the operations within the border of a company but also paves the way for better resource sharing and demand matching among different companies. Gebresenbet et al. (2018) developed a web-based smart platform for quality control, traceability, and demand matching and optimization of farmers, transporters, and customers in a reverse logistics system for biomass recovery and trading. Liu (2015) investigated a data-driven logistics information system for smart collaborations among different stakeholders, e.g., governments, banks, facilities, service providers, and customers, to achieve rapid decision making, cost reduction, and high-quality services. To evaluate the effectiveness of Industry 4.0 enabled sustainable logistics systems, simulation models can be used to provide quantitative insights. By using simulation models, Zissis et al. (2018) analyzed the cost reduction and service level of the smart collaborations for the home delivery of online groceries.

Considering both economic and environmental sustainability, Mastos et al. (2020) proposed an Industry 4.0 enabled forward-reverse logistics system for effective treatment of hazardous chemicals. At the intra-company level, this system enables effective logistics operations including the data-driven collection of hazardous chemicals, proactive maintenance of equipment, vehicle monitoring, data visualization, and decision optimization. At the intercompany level, a cloud-based collaborative ecosystem is established for effective demand matching and cooperation. From the corporate social sustainability perspective, Daú et al. (2019) discussed the application of IoT and other smart technologies to improve the sustainable practices of healthcare logistics.

Blockchain is another important technology for the digitalization of a logistics system and the integration of smart devices and platforms for data sharing and virtual currency transactions. It improves transparency, traceability, and security at every stage of logistics operations (Kouhizadeh et al. 2021) through the tracking of information, physical components, transactions, and participants' actions and behaviors (Bai and Sarkis 2020), which facilitates the capability of conflict management (Manupati et al. 2020) and risk mitigation (Kodym et al. 2020) in the entire logistics system. This also paves the way for sustainable collaboration among different stakeholders in a trustworthy business environment (Cole et al. 2019). Besides, the opportunities for using blockchain-based digital systems to improve the environmental performance of logistics operations through life cycle assessment have also been discussed (Zhang et al. 2020).

\section{Discussions}

In this section, the opportunities and challenges for sustainable logistics in the Industry 4.0 era are first discussed, and the suggestions for future research are then given.

\section{Opportunities}

Increasing attention has been paid to improve the sustainability of logistics systems with Industry 4.0 technologies, and worldwide efforts have been spent to advance theoretical development, technology transfer, business model innovation, and industrial applications. Based on the content analysis, Fig. 9 summarizes the impacts of Industry 4.0 technologies on the economic, environmental, and social dimensions of sustainable logistics. The technological revolution provides companies with opportunities to transform their logistics operations to become more responsive to external market changes, while simultaneously being efficient with internal operations. On the one hand, through small-scale localized production with $\mathrm{AM}$ and autonomous robots, new business opportunities arise with increasing demands of individualized customizations and product-related services (Yu and Solvang 2017), and this requires service innovation and improvement of logistics operations. Furthermore, the web-based information-sharing systems improve service level and customers' experiences by a high level of customer involvement throughout the design, production, and delivery processes. On the other hand, the integration of IoT, big data analytics, and AI algorithms via cloud-based platforms provides computing power to handle multi-sourced large volume data, which can be used for better visualization and analysis of some key parameters (Bourke 2019, Abbas and Marwat 2020), i.e., demand trends and maintenance requirements ( $\mathrm{Li}$ et al. 2017). Furthermore, using better data as inputs to optimization and simulation models, important logistics decisions (da Silva et al. 2017), e.g., production planning, inventory management, routing, and delivery schedules, can be made in a timely and more accurate manner (Zhang 2018).

The most important characteristic of an Industry 4.0 enabled sustainable logistics system is data-driven proactive planning, real-time decision making, and autonomous operations. This high-level digitalization and system integration have led to the conceptual architecture of the digital twin of logistics systems (Ivanov and Dolgui 2020). The digital twin of a logistics system is fully 


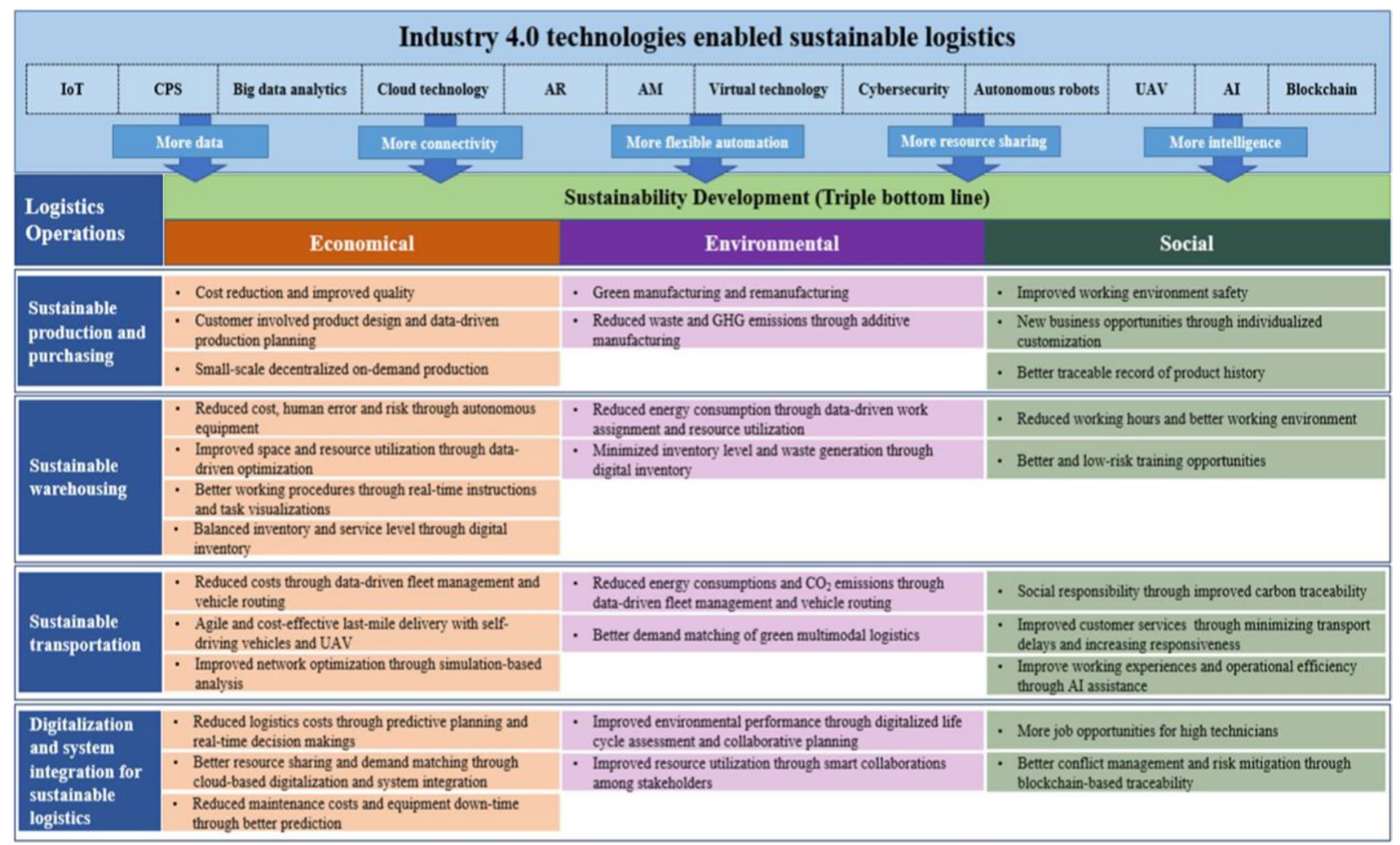

Fig. 9 Sustainable logistics enabled by Industry 4.0 technologies

driven by the data collected from both cyber and physical sources (Wang and Wang 2019), e.g., smart sensors and enterprise resource planning (ERP), and it is capable of proactive planning with better analytics of historical data and reactive decision making and scenario analysis with real-time data. From the socio-economic perspective, information sharing among companies in a logistics system and the use of data analytics provide opportunities for better demand matching, resource sharing, and facility usage. The use of autonomous robots and UAV minimizes errors, risks, and labor costs of production, warehousing, and transportation while, simultaneously, provides innovative and environmentally friendly ways of goods delivery (Wen et al. 2018). For instance, logistics information sharing and autonomous equipment are particularly important during the COVID-19 outbreak, which can help to minimize the shortage of emergency medical supplies and to effectively allocate and deliver them to the demand regions.

Better resource planning reduces waste generation and environmental footprints at different stages of a logistics system. Besides, the cloud-based information system provides opportunities to monitor the entire product life cycle and promote effective cloud-based remanufacturing and recycling when they become EOL products (Wang and Wang
2019). From the social sustainability perspective, the adoption of blockchain technologies provides better traceability and more trustworthy business environments in logistics systems. The increased use of autonomous devices improves the safety and working environment of various logistics operations. AI-enabled virtual technologies and AR provide logistics operators with risk-free training, virtual assistance, and real-time task instructions and visualization to improve their working experiences and effectiveness (Ebinger and Omondi 2020, Felstead 2019). In addition, with the requirements of increased digitalization, hardware and software development, and system integration, new job opportunities can be created in the logistics sector as well as in the other related industries.

\section{Challenges and gaps}

Most articles focus on how Industry 4.0 supports sustainable logistics, but less effort has been paid to understand the challenges of this digital transformation. Even though the new technologies have provided many opportunities, they also bring several challenges for sustainable logistics. One example is shown by China's rapidly developing express delivery and food delivery systems due to the booming of e-commerce. On the one hand, thanks to the better demand 
allocation and order tracking system empowered by AI, IoT, and advanced optimization, customers can now enjoy cheaper and faster delivery services of their foods and merchandise ordered online. However, on the other hand, these responsive logistics services require much more frequent last-mile deliveries, which lead to more traffic congestions and carbon emissions. Furthermore, the online platform assigns strict requirements to ensure on-time delivery, which raises concerns about the safety issues and job satisfaction of the deliverymen. Thus, we discuss several main challenges and gaps of sustainable logistics in the Industry 4.0 era:

- Lack of a holistic consideration of multiple sustainable indicators: A sustainable logistics system balances the trade-off among the economic, environmental, and social dimensions. However, this has not been holistically considered in the adoption of Industry 4.0. For instance, the delivery allocation algorithm of the online food ordering platforms is designed to maximize the service level so that customer satisfaction and economic sustainability can be enhanced, but more environmental and safety issues are not considered holistically.

- Unclear economic benefits and the impacts of other sustainability indicators: Compared with the development of technologies, less effort has been spent on the development of quantitative and analytical methods (Karakikes and Nathanail 2017) to evaluate the economic benefits and the impacts of other sustainability indicators by adopting Industry 4.0 in logistics systems. For example, using robots to replace manual operations in a warehouse not only affects a single activity but also largely influences other operations and the performance of the whole logistics system. Several studies show that the lack of concrete evidence on performance improvement has become a major hindrance to confirming companies to adopt Industry 4.0 in their logistics operations (Luthra and Mangla 2018).

- Lifecycle energy consumption and environmental footprint: Even if Industry 4.0 shows the potential to reduce waste generation and improve resource utilization, from the lifecycle analysis perspective, the use of a large number of sensors, robots, and other smart devices in various logistics operations has inevitably led to higher energy consumption and potential environmental footprints. For example, UAV is believed an environmentally friendly way to provide responsive and low-carbon delivery service. However, the recent research by Stolaroff et al. (2018) has shown that the environmental footprints of UAV delivery may be higher than the traditional road delivery due to its limited capacity.
- Job loss and difficulties for workers: Logistics is a laborintensive industry, and there is not a high requirement of knowledge and education for first-line operators. On the one hand, the human-centered technological revolution improves logistics operations, efficiency, agility, safety, and working environment. However, on the other hand, from the social sustainability perspective, it will inevitably cause job losses, the anxiety of employees who worry about their careers, and difficulties especially for aging workers both technically and psychologically to adapt to this new transformation.

- Inequity issues: The paradigm change of sustainable logistics is led by the market leaders like DHL, Amazon, and JD.COM, who spent large investments for developing smart and autonomous logistics solutions (Olsen and Tomlin 2020). However, the lack of financial and technological resources of small and medium-sized enterprises (SMEs) significantly hinders the adoption of smart technologies and sustainable practices in their logistics systems, which results in an unequal position in the competition with large companies. In addition, studies also reveal that some Industry 4.0 technologies, e.g., big data analytics, can be used for unfair price discrimination and dynamic pricing throughout different players in a logistics system (Jagtap et al. 2021).

- Lack of a general guideline: The current research focuses on the adoption of an individual or several Industry 4.0 technologies in sustainable logistics. However, the practices are ad-hoc endeavors, and there is a lack of systematic guidelines to link different Industry 4.0 technologies and sustainable logistics operations at various stages.

- System integration and interoperability: The meaning of interoperability is that different smart devices and systems can independently communicate and access each other's functions (Phuyal et al. 2020). Implementing Industry 4.0 in a sustainable logistics system that has many devices for different operations requires not only technological upgrades but also system integration with existing equipment. The communication protocols and control methods of the existing equipment and the new devices or system are by no means identical, so large efforts and upfront costs are required to make the existing logistics system more autonomous, smart, and sustainable.

- Data quality and cybersecurity concerns: Industry 4.0 requires effective data sharing horizontally among different facilities and companies in a logistics system and vertically throughout different functions and operations within a company (Foidl and Felderer 2015). However, the maturity and quality of data processing at different companies may not be at the same level, so this techno- 
logical transformation requires collaborative efforts from various stakeholders in a logistics network. Besides, the concerns of cybersecurity and data safety also hinder the adoption of Industry 4.0 in logistics operations (Phuyal et al. 2020).

In addition, there exist knowledge siloing of current research. Industry 4.0 enabled sustainable logistics is a topic related to several subjects, e.g., computer and data sciences, automation and control, robotics, operations research, and social science. However, from the bibliometric analysis, it is evident that there is still a lack of effective research cooperation among researchers and groups with different backgrounds and geographical locations. This limits the generation of a general guideline and solution that can be widely applicable in different regions.

\section{Future research suggestions}

Several research directions are recommended to fill the literature gaps and better support this smart transformation of sustainable logistics:

1. Human-centric smart logistics transformation needs to be focused on. The latest concept of Industry 5.0 extends the technology-centric transformation of Industry 4.0 to a more socially sustainable human-centric transformation, and future research is thus needed to understand how human-centric smart transformation can be achieved in logistics sectors. Besides, several social impacts such as the demographic change and the impacts to aging workers for adopting these smart technologies in logistics sectors need to be better understood.

2. Multi-objective balanced system design for sustainable logistics operations. This requires new algorithms and systems that are designed to help with decisionmaking considering multiple objectives. For example, in the order allocation algorithm for food delivery assignment, a balance needs to be achieved among the service level, the environmental footprints, and the deliverymen's safety issues in the real-time traffic condition.

3. The lifecycle environmental impact of Industry 4.0 enabled logistics systems needs to be better analyzed. Future studies are needed to provide deeper insights into the environmental footprints through lifecycle analysis. For instance, the system boundary of the analysis should be extended to the energy consumption and resource usage related to the production and recycling of the smart devices used in sustainable logistics.
4. Analytical models and optimization for adopting Industry 4.0 technologies in smart ways in different logistics operations and for providing quantitative implications of the cost benefits, different sustainability indicators, and overall system performance. Besides, in the Industry 4.0 era, the logistics system's effectiveness, efficiency, flexibility, agility, and environmental footprints need probably to be re-balanced (Olsen and Tomlin 2020), which requires better-designed analytical tools and optimization algorithms.

5. The digital twin of sustainable logistics systems needs to be focused to provide end-to-end solutions to various logistics operations. Via a cloud-based system, the predictive analytics with $\mathrm{AI}$ and the real-time data from IoT sensors as well as other cyber and physical portals need to be seamlessly connected with analytical optimization and simulation tools to improve both proactive and real-time decision making in sustainable logistics operations. Besides, future research is also suggested to develop the bi-directional control architecture to achieve highly autonomous logistics operations, e.g., warehousing.

6. Semi-autonomous sustainable transportation solutions: Even if autonomous driving vehicles have been extensively focused on in recent years, the realization of a fully autonomous transportation system faces many challenges and uncertainties, i.e., legal restrictions, technological maturity, and safety issues. Thus, the use of semi-autonomous solutions is an attractive alternative for sustainable logistics solutions. For example, truck platooning is a semi-autonomous system that has several benefits, e.g., improved efficiency, reduced labor costs, and reduced fuel consumption and carbon emissions due to the reduction of the aerodynamic resistance of the following trucks.

7. Broad and diversified technology focus should be given not only to IoT, CPS, AI, and autonomous robots but also to others, e.g., AR and AM, which receive much less attention in the literature related to sustainable logistics. Thus, future research is needed to provide a better understanding of how those Industry 4.0 can be used to enhance sustainable logistics operations.

8. Sustainable reverse logistics enabled by Industry 4.0 is another opportunity for future research. Less focus has been given to the smart transformation of reverse logistics, which faces challenges related to the uncertainty of the market demands and the quantity and quality of the returned products. Smart technologies provide opportunities for minimizing the impact of uncertainty with better prediction and for more effective resource sharing among different companies. 
Besides, the use of AI-enabled autonomous robots has shown potentials to replace human workers from harsh working environments, e.g., manual sorting of waste. In addition, the terms "demand individualization" and "individualized customization" need to be redefined in reverse logistics.

9. The smart and sustainable logistics solutions for the COVID-19 need to be focused on. Due to the rapidly increased demand, strict border control and city lockdown, and reduced transportation capacity, the COVID-19 pandemic has hindered the flows of goods, increased logistics costs, and imposed a higher risk on vulnerable groups related to the shortage of medical supplies, foods, and other necessities. In this regard, the role of Industry 4.0 technologies needs to be highlighted to tackle the logistics challenges during the pandemic. For example, the use of robots to collect infectious waste at healthcare facilities may reduce the infection risks.

\section{Conclusions}

The concepts of sustainable logistics and Industry 4.0 have been focused on by many researchers due to the increasing need for technology-driven smart and sustainable logistics. This paper provides a systematic literature review focusing on the recent development and adoption of various Industry 4.0 technologies in sustainable logistics at both intra- and inter-company levels. First, a bibliometric analysis was conducted to identify the publication trend, the most influential journals and research, the co-citation networks, and the most frequently used keywords. Then, a content analysis was performed to understand the current research landscape on how Industry 4.0 technologies can be used to improve sustainable logistics activities, namely, production and purchasing, warehousing, transportation, and general system integration. Finally, current research developments were summarized, and the challenges, literature gaps, and future research opportunities were discussed. To answer the proposed research questions:

- $R Q 1$, we systematically analyze the state-of-the-knowledge of Industry 4.0 and sustainable logistics with both bibliometric analysis and content analysis in the "Bibliometric analysis" and "Content analysis" sections.

- $R Q 2$, we thoroughly discuss both the opportunities and the challenges of sustainable logistics in the Industry 4.0 era in the "Opportunities" and "Challenges and gaps" sections.
- $R Q 3$, we identify 9 future research directions in the "Future research suggestions" section.

From the research perspective, the results show an increasing focus has been given to Industry 4.0 enabled sustainable logistics, which is an area attracting worldwide researchers and practitioners. The results suggest that cooperation among researchers should be enhanced in the future. In addition, the paper analyses the current research landscape and how the paradigm shift of various logistics activities is driven by technological advancements, and their implications on improving economic, environmental, and social sustainability are discussed. Based on this, the gaps and opportunities are identified to guide future research.

From the practical perspective, the results provide insights for the potential application of Industry 4.0 technologies to enhance sustainable logistics practices, which will promote knowledge transfer from academic research to industrial applications. In particular, the use of data-driven decision-support platforms may provide cost-effective, safe, and reliable tools for a better understanding and analysis of the effectiveness and challenges of adopting new technologies, digital solutions, and business models in sustainable logistics systems. From a broader perspective, these discussions also provide other companies with implications and some successful examples for guiding their logistics transformations in the Industry 4.0 era. Besides, the challenges of Industry 4.0 to sustainable logistics systems need to be noticed in this technological and operational transformation. One should bear in mind that the benefits should never be overestimated, and the challenges and commitments required should never be underestimated.

The paper inevitably has several limitations regarding the filters used in the sample selection, which only account for the journal articles published in English with respect to the selected keywords, the two databases, and the time of the search. Sustainable logistics and Industry 4.0 are extensively focused by worldwide researchers, and some important publications may be published in different languages. Besides, both concepts are currently getting fastgrowing attention, and relevant papers may be published in different forms, i.e., conference papers, book chapters, magazines, industrial reports, or under the peer-review stage as pre-prints. Therefore, the results presented in this paper are not exhaustive, and future improvements are needed to present a more comprehensive analysis with an extended sample selection. 


\section{Appendix 1}

Table 4 The clusters, the occurrences, and the TLSs of the highly used keywords (The maximum number of keywords included from each cluster is 10)

\begin{tabular}{|c|c|c|c|}
\hline Clusters & Keywords & Occurrences & TLS \\
\hline \multirow[t]{10}{*}{ Cluster 1} & Internet of things & 21 & 117 \\
\hline & Decision making & 19 & 115 \\
\hline & Smart logistics & 17 & 52 \\
\hline & Cloud computing & 5 & 18 \\
\hline & Logistics industry & 5 & 18 \\
\hline & Warehouses & 5 & 21 \\
\hline & Carbon & 4 & 24 \\
\hline & Embedded systems & 4 & 29 \\
\hline & Information platform & 4 & 8 \\
\hline & IoT & 4 & 21 \\
\hline \multirow[t]{10}{*}{ Cluster 2} & Article & 8 & 100 \\
\hline & Big data & 8 & 61 \\
\hline & Blockchain & 8 & 75 \\
\hline & Human & 8 & 100 \\
\hline & Circular economy & 7 & 68 \\
\hline & Information management & 6 & 50 \\
\hline & Sustainable supply chain management & 6 & 36 \\
\hline & Economic aspect & 5 & 58 \\
\hline & Data analytics & 4 & 50 \\
\hline & Environmental sustainability & 4 & 46 \\
\hline \multirow[t]{10}{*}{ Cluster 3} & Supply chain management & 39 & 264 \\
\hline & Sustainability & 29 & 191 \\
\hline & Sustainable development & 28 & 220 \\
\hline & Sustainable supply chains & 28 & 235 \\
\hline & Supply chains & 13 & 94 \\
\hline & Optimization & 10 & 51 \\
\hline & Supply chain & 8 & 56 \\
\hline & Simulation & 7 & 32 \\
\hline & Sustainable supply chain & 7 & 46 \\
\hline & Environmental impact & 5 & 43 \\
\hline \multirow[t]{10}{*}{ Cluster 4} & Cost reduction & 3 & 16 \\
\hline & Design/methodology/approach & 4 & 32 \\
\hline & Economic and social effects & 3 & 28 \\
\hline & Environmental pollutions & 3 & 20 \\
\hline & Hazardous chemicals & 3 & 13 \\
\hline & Hazardous materials & 3 & 13 \\
\hline & Hazards & 3 & 13 \\
\hline & Industrial economics & 4 & 35 \\
\hline & Industrial research & 3 & 21 \\
\hline & Internet of things (iot) & 9 & 68 \\
\hline
\end{tabular}

Table 4 (continued)

\begin{tabular}{llll}
\hline Clusters & Keywords & Occurrences & TLS \\
\hline Cluster 5 & Industry 4.0 & 34 & 151 \\
& Logistics & 14 & 59 \\
& Logistics 4.0 & 10 & 18 \\
& Artificial intelligence & 9 & 53 \\
Decision support systems & 9 & 57 \\
Decision support system & 4 & 29 \\
Bibliometric analysis & 3 & 16 \\
& Food supply & 3 & 17 \\
Industrial revolutions & 3 & 14 \\
Manufacturing & 3 & 14 \\
Cluster 6 & Arveys & 5 & 37 \\
Analytic hierarchy process & 3 & 27 \\
Analytical hierarchy process & 3 & 27 \\
Analytic hierarchy process (ahp) & 3 & 21 \\
Accident prevention & 3 & 16 \\
\hline
\end{tabular}




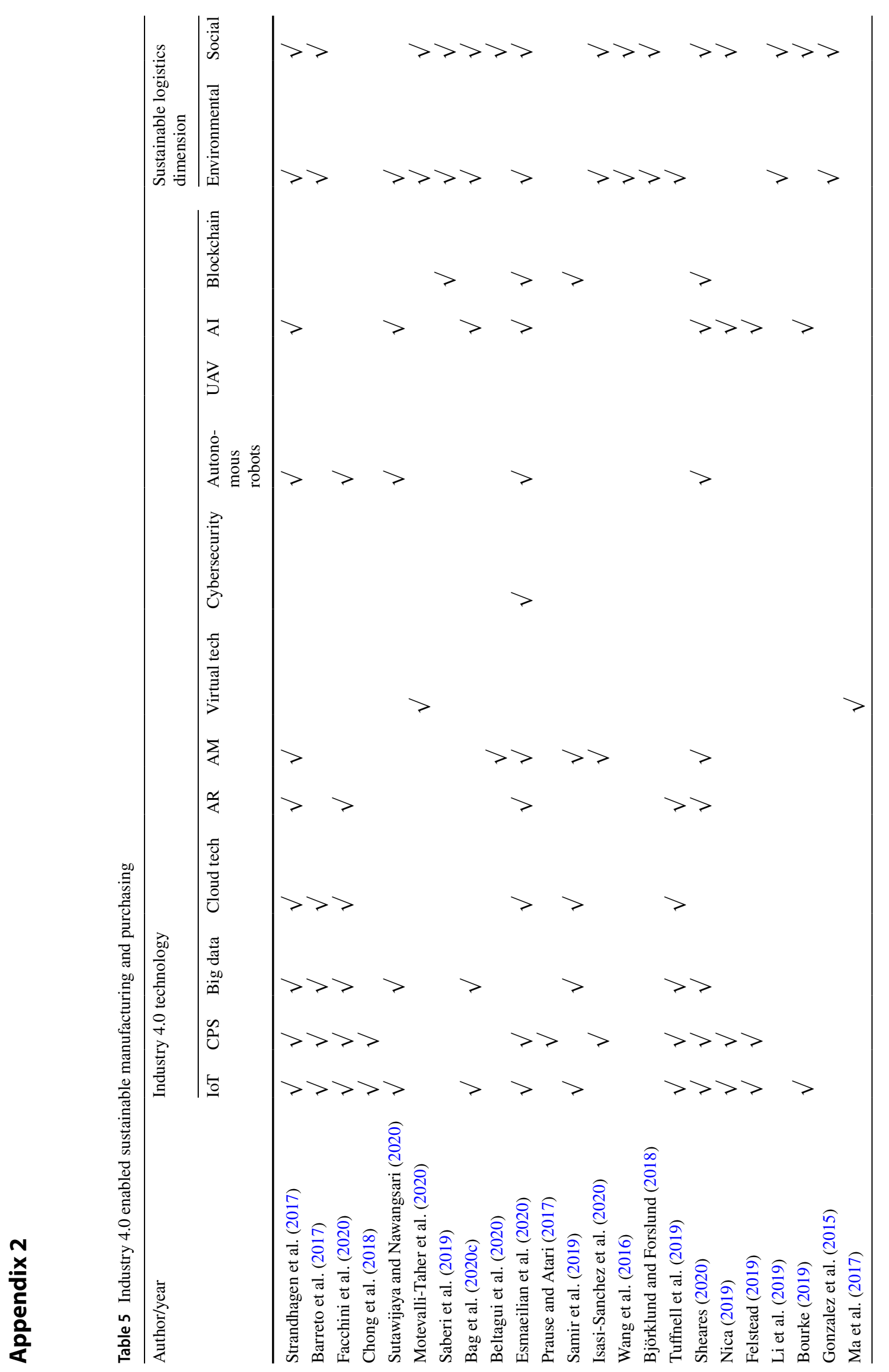




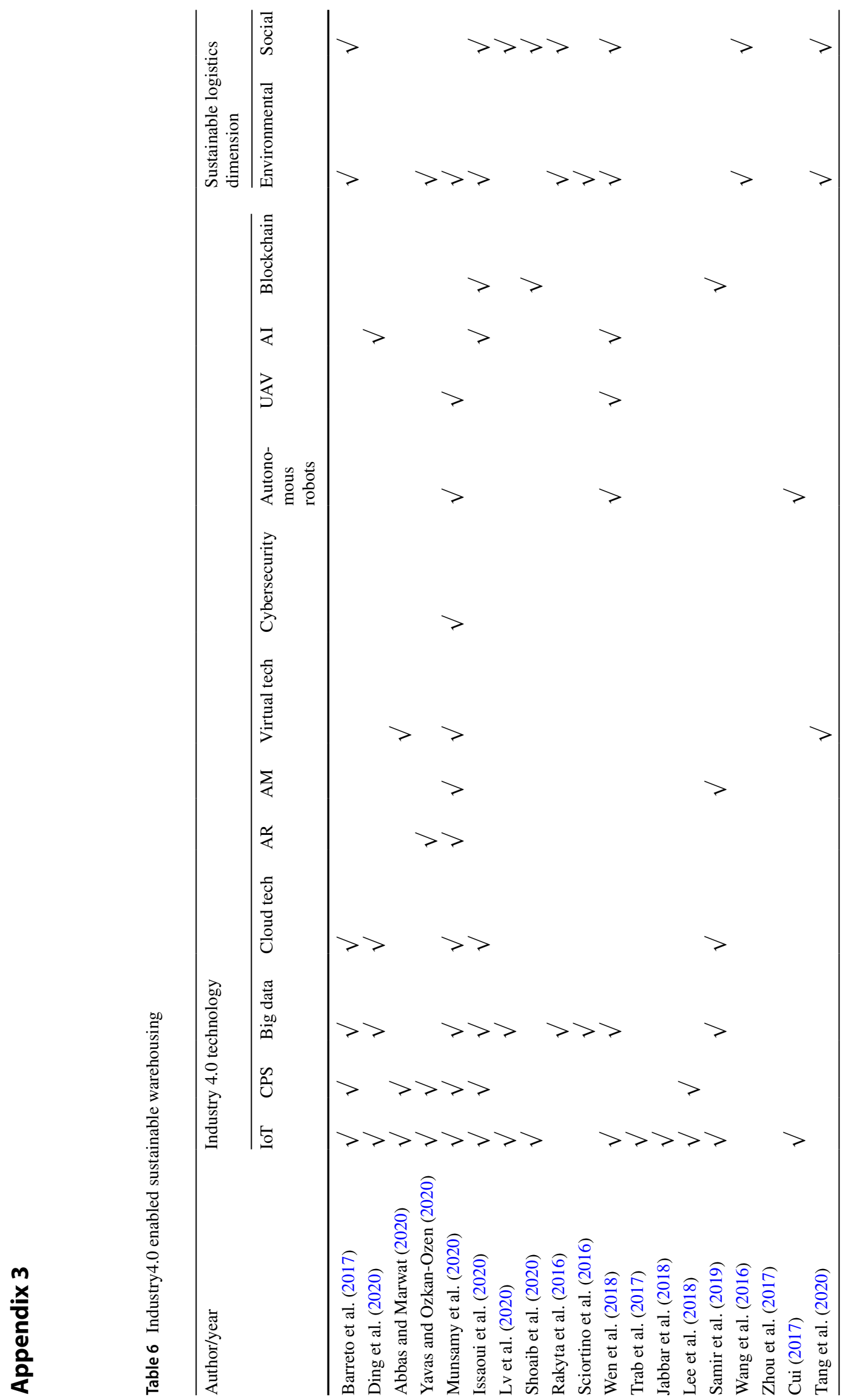




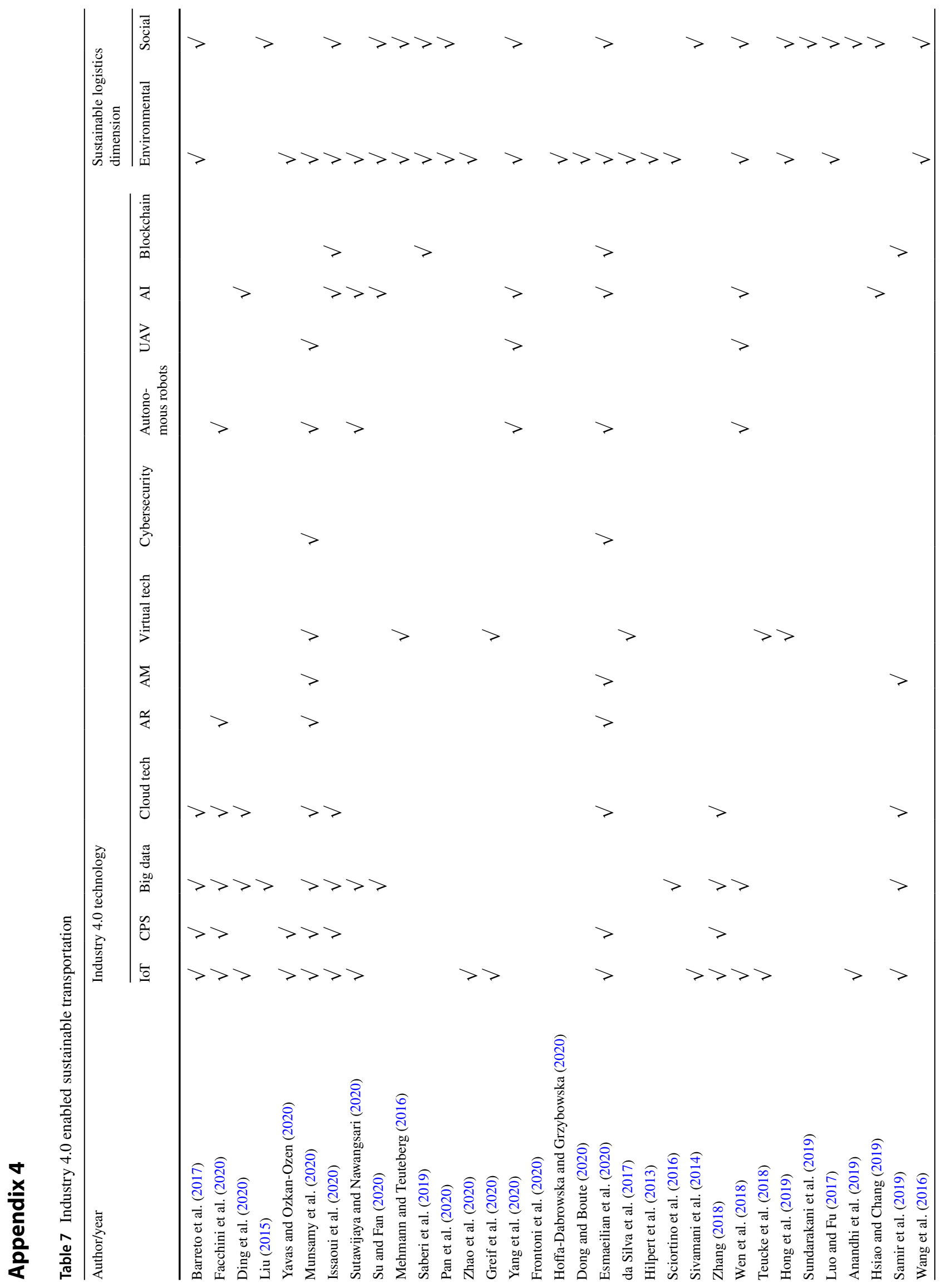




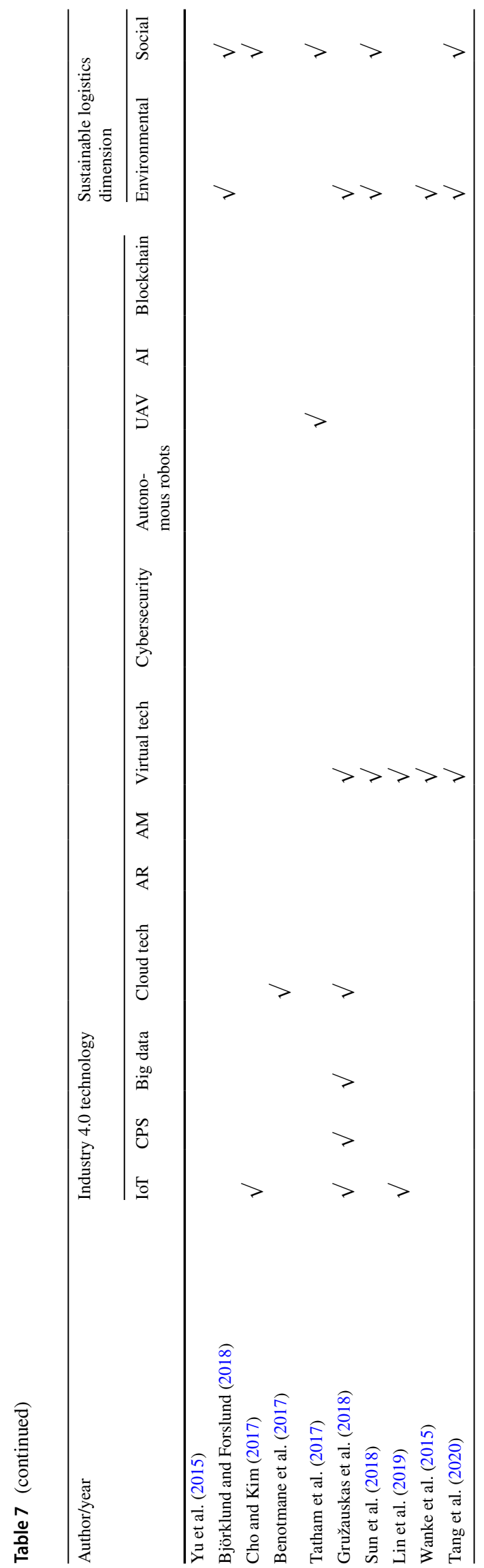




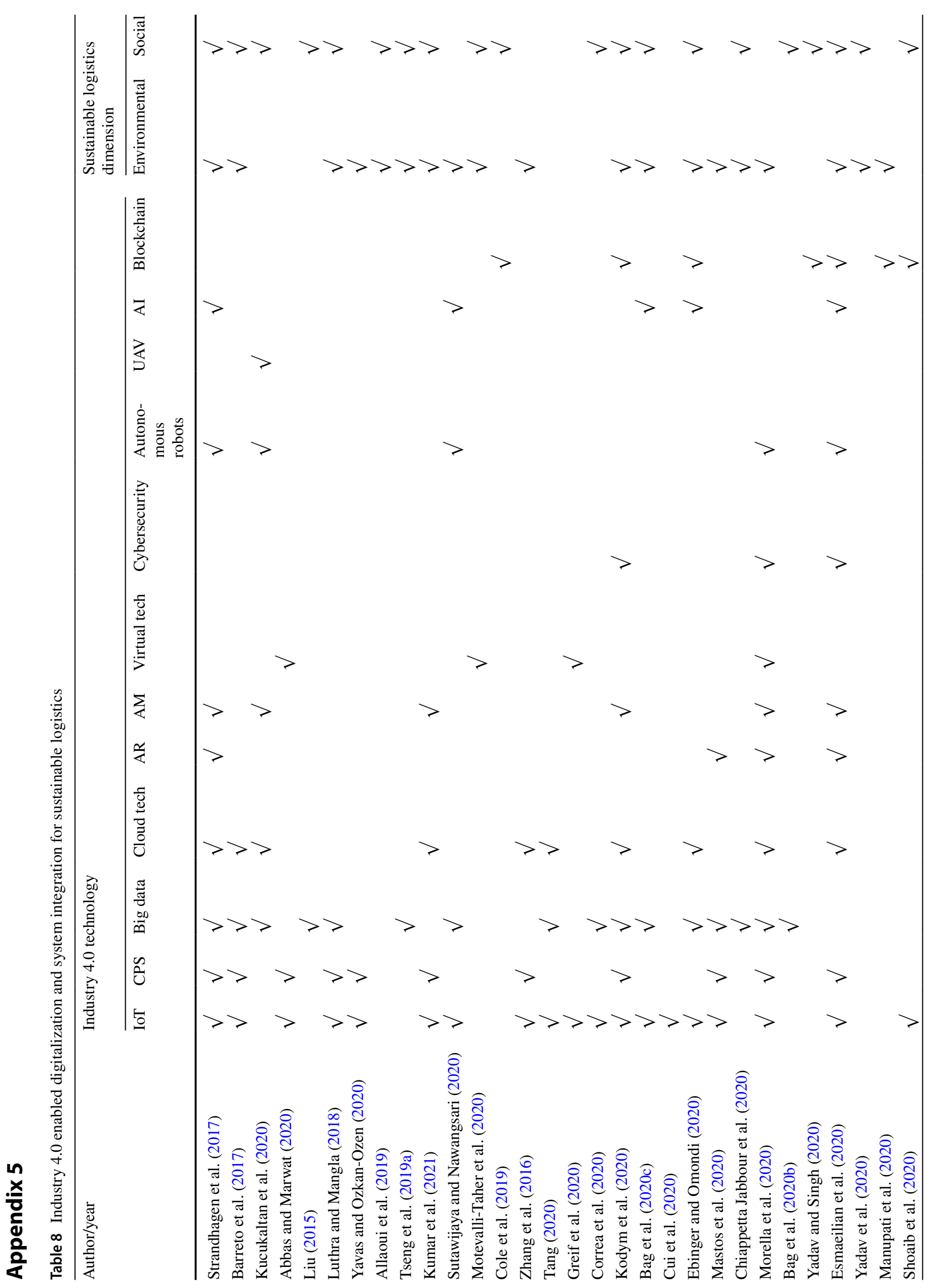




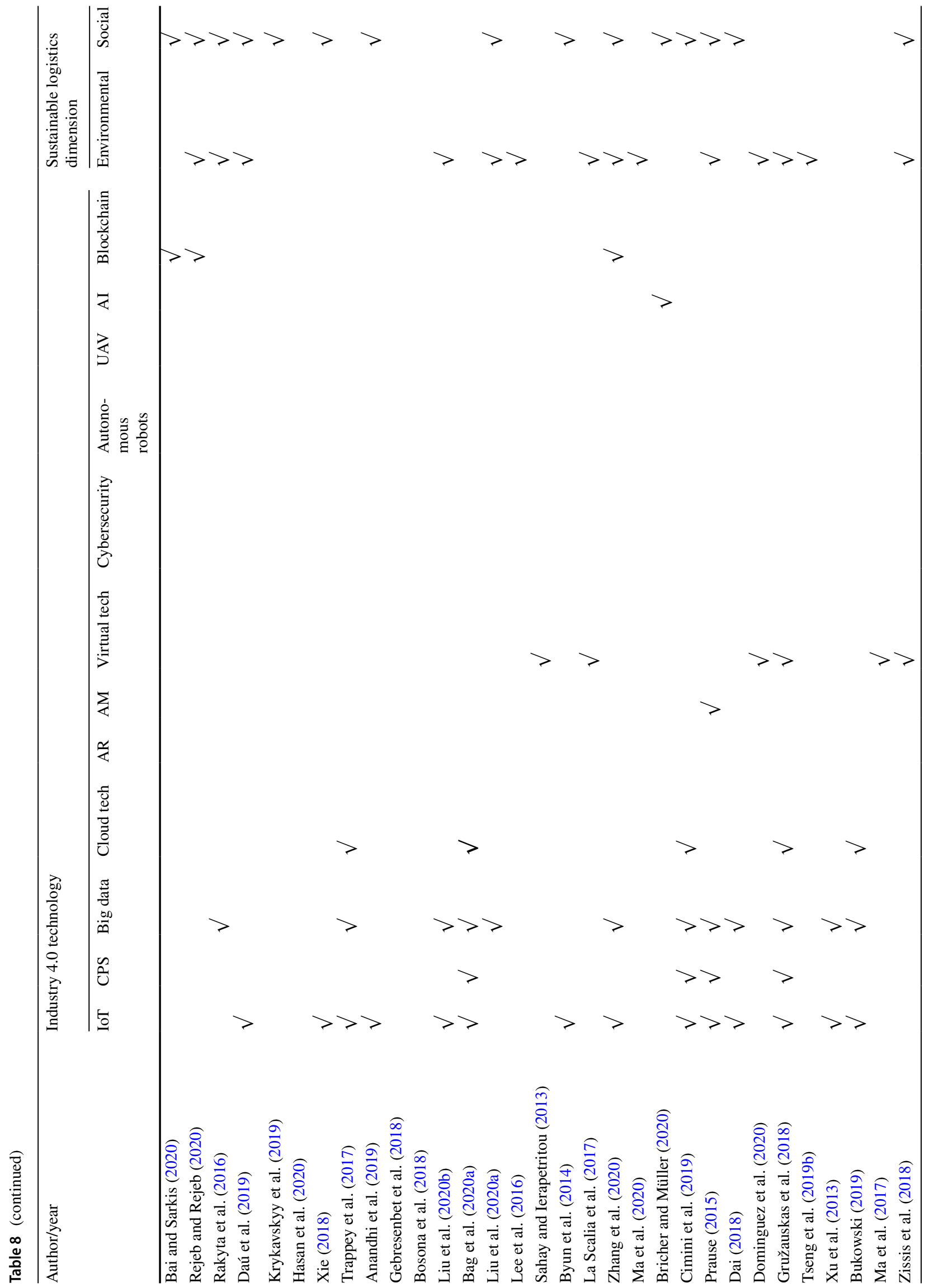


Author contribution Conceptualization: X.S., H.Y., W.D.S.

Methodology: X.S., H.Y.

Data curation: X.S.

Formal analysis: X.S., H.Y.

Supervision: W.D.S

Writing—original draft: X.S.

Writing—review and editing: X.S., H.Y., W.D.S., Y.W., K.W.

Funding Open Access funding provided by UiT The Arctic University of Norway

Data Availability Not applicable.

\section{Declarations}

Ethics approval and consent to participate Not applicable.

Consent for publication Not applicable.

Competing interests The authors declare no competing interests.

Open Access This article is licensed under a Creative Commons Attribution 4.0 International License, which permits use, sharing, adaptation, distribution and reproduction in any medium or format, as long as you give appropriate credit to the original author(s) and the source, provide a link to the Creative Commons licence, and indicate if changes were made. The images or other third party material in this article are included in the article's Creative Commons licence, unless indicated otherwise in a credit line to the material. If material is not included in the article's Creative Commons licence and your intended use is not permitted by statutory regulation or exceeds the permitted use, you will need to obtain permission directly from the copyright holder. To view a copy of this licence, visit http://creativecommons.org/licenses/by/4.0/.

\section{References}

Abbas AW, Marwat SNK (2020) Scalable emulated framework for IoT devices in smart logistics based cyber-physical systems: bonded coverage and connectivity analysis. IEEE Access 8:138350-138372

Abdirad M, Krishnan K (2021) Industry 4.0in logistics and supply chain management: A systematic literature review. Eng Manag J 33(3):187-201

Allaoui H, Guo Y, Sarkis J (2019) Decision support for collaboration planning in sustainable supply chains. J Clean Prod 229:761-774

Álvarez E, de la Calle A (2011) Sustainable practices in urban freight distribution in Bilbao. J Ind Eng Manag 4:538-553

Anandhi S, Anitha R, Sureshkumar V (2019) IoT enabled RFID authentication and secure object tracking system for smart logistics. Wireless Pers Commun 104:543-560

ANURAG 2020. Augmented Reality will change the way you do business. Accessed on: https://www.newgenapps.com/blog/augme nted-reality-will-change-the-way-you-do-business/ [23.07.2020].

Azarian M, Yu H, Solvang WD, Shu B (2019) An introduction of the role of virtual technologies and digitaltwin in industry 4.0. In International Workshop of Advanced Manufacturing and Automation. Springer, Singapore, pp 258-266

Bag S, Gupta S, Luo Z (2020a) Examining the role of logistics 4.0 enabled dynamic capabilities on firm performance. Int J Logist Manag 31:607-628
Bag S, Telukdarie A, Pretorius JHC, Gupta S (2018) Industry 4.0 and supply chain sustainability: framework andfuture research directions. BIJ 28(5):1410-1450

Bag S, Wood LC, Xu L, Dhamija P, Kayikci Y (2020) Big data analytics as an operational excellence approach toenhance sustainable supply chain performance. Resour Conserv Recycl 153:104559

Bag S, Yadav G, Wood LC, Dhamija P, Joshi S (2020) Industry 4.0 and the circular economy: resource melioration inlogistics. Resour Policy 68:101776

Baheti R, Gill H (2011) Cyber-physical systems. The Impact of Control Technology 12:161-166

Bai C, Sarkis J (2020) A supply chain transparency and sustainability technology appraisal model for blockchain technology. Int J Prod Res 58:2142-2162

Barreto L, Amaral A, Pereira T (2017) Industry 4.0 implications in logistics: an overview. Procedia Manuf 13:1245-1252

Beier G, Ullrich A, Niehoff S, Reißig M, Habich M (2020) Industry 4.0: How it is defined from a sociotechnicalperspective and how much sustainability it includes-A literature review. J Clean Prod 259:120856

Bekey GA (2005) Autonomous robots:from biological inspiration to implementation and control. MIT press, Cambridge, MA

Beltagui A, Kunz N, Gold S (2020) Therole of 3D printing and open design on adoption of socially sustainable supplychain innovation. Int J Prod Econ 221:107462

Beltrami M, Orzes G, Sarkis J, Sartor M (2021) Industry 4.0 and sustainability: Towards conceptualization andtheory. J Clean Prod 312:127733

Benotmane Z, Belalem G, Neki A (2017) A cloud computing model for optimization of transport logistics process. Transp Telecommun 18:194-206

Birkel HS, Müller JM (2020) Potentialsof industry 4.0 for supply chain management within the triple bottom line ofsustainability-A systematic literature review. J Clean Prod 289:125612

Björklund M, Forslund H (2018) Aframework for classifying sustainable logistics innovations. Logist Res 11(1):1-12

Bosona T, Gebresenbet G, Olsson SO,Garcia D, Germer S (2018) Evaluation of a smart system for theoptimization of logistics performance of a pruning biomass value chain. Appl Sci 8(10):198

Bourke E (2019) Smart production systems in industry 4.0: Sustainable supply chain management, cognitive decision-making algorithms, and dynamic manufacturing processes. J Self-Gov Manag Econ 7:25-30

Brandenburg M, Govindan K, Sarkis J, Seuring S (2014) Quantitative models for sustainable supply chain management: Developments and directions. Eur J Oper Res 233:299-312

Bricher D, Müller A (2020) A supervisedmachine learning approach for intelligent process automation in container logistics. J Comput Inf Sci Eng 20(3),paper no. JCISE-19-1172

BRUNDTLAND 1987. The Brundtland report: 'Our common future'. Accessed on https://www.are.admin.ch/are/en/home/sustainabledevelopment/international-cooperation/2030agenda/un-_-miles tones-in-sustainable-development/1987--brundtland-report.html [25.05.2020].

Bukowski L (2019) Logistics decision-making based on the maturity assessment of imperfect knowledge. Eng Manag Prod Serv 11:65-79

Byun JY, Nasridinov A, Park YH (2014) Internet of things for smart crime detection. Contemp Eng Sci 7:749-754

Cavinato J (1982) The traffic service corporation. The Traffic Service Corporation, Washington, DC

Chalmeta R, Santos-Deleón NJ (2020) sustainable supply chain in the era of Industry 4.0 and big data: a systematic analysis of literature and research. Sustainability 12:4108

Chiappetta Jabbour CJ, Fiorini PDC,Ndubisi NO, Queiroz MM, Piato ÉL (2020) Digitally-enabledsustainable supply chains 
in the 21st century: A review and a researchagenda. Sci Total Environ 725:138177

Cho S, Kim J (2017) Smart logistics model on internet of things environment. Adv Sci Lett 23:1599-1602

Chong ZQ, Low CY, Mohammad U, Rahman RA, Shaari MSB (2018) Conception of logistics management system for smart factory. IJET (UAE) 7:126-131

M Christopher (2016) Logistics \& supply chain management. Pearson, UK

Cimini C, Lagorio A, Pirola F, Pinto R (2019) Exploring human factors in Logistics 4.0: empirical evidence from acase study. IFAC-PapersOnLine 52(13):2183-2188

Cole R, Stevenson M, Aitken J (2019) Blockchain technology: implications for operations and supply chain management. Supply Chain Manag 24:469-483

Correa JS, Sampaio M, DE CASTO BARROS, R. \& DE CASTRO HILSDORF, W. (2020) IoT and BDA in the Brazilian future logistics 4.0 scenario. Producao 30:1-14

Craigen D, Diakun-Thibault N, Purse R (2014) Defining cybersecurity. Technol Innov Manag Rev 4(10):13-21

Cui L, Gao M, Dai J, Mou J (2020) Improving supply chain collaboration through operational excellence approaches:an IoT perspective. Ind Manag Data Syst. https://doi.org/10.1108/ IMDS-01-2020-0016

Cui W (2017) An optimization model for storage robot adaptive positioning system (SR-APS) and simulation analysis. Boletin Tecnico/technical Bulletin 55:484-491

da Silva FF, Rangel JJA, Peixoto TA, Matias ÍO, Tavares ER (2017) Simulation optimization for analysis of sustainable logistics systems. Pesqui Operacional 37:145-171

Dai Y (2018) Exploring the scale application of internet of things in the field of smart logistics. IPPTA: Q J Indian Pulp Pap Tech Assoc 30:414-418

Daú G, Scavarda A, Scavarda LF, Portugal VJT (2019) The healthcare sustainable supply chain 4.0: Thecircular economy transition conceptual framework with the corporate socialresponsibility mirror. Sustainability 11(12):3259

Davarzani H, Fahimnia B, Bell M, Sarkis J (2016) Greening ports and maritime logistics: a review. Transp Res Part d: Transp Environ 48:473-487

Dekker R, Bloemhof J, Mallidis I (2012) Operations Research for green logistics-an overview of aspects, issues, contributions and challenges. Eur J Oper Res 219:671-679

Dey A, Laguardia P, Srinivasan M (2011) Building sustainability in logistics operations: A research agenda. Manag Res Rev 34:1237-1259

Ding Y, Jin M, Li S, Feng D (2021) Smart logistics based on the internet of things technology: an overview. Int J Logist Res Appl 24(4):323-345

Dominguez R, Cannella S, Framinan JM (2021) Remanufacturing configuration in complex supply chains. Omega 101:102268

Dong C, Boute R (2020) The beer transportation game: How to decarbonize logistics by moving freight to sustainable transport modes. INFORMS Trans Educ 20:102-112

Ebinger F, Omondi B (2020) Leveragingdigital approaches for transparency in sustainable supply chains: A conceptualpaper. Sustainability 12(15):6129

Ejsmont K, Gladysz B, Kluczek A (2020) Impact of Industry 4.0 on Sustainability—Bibliometric Literature Review. Sustainability 12:5650

Esmaeilian B, Sarkis J, Lewis K, Behdad S (2020) Blockchain for the future of sustainable supply chain management in Industry 4.0. Resour Conserv Recycl 163:105064

Evangelista P, Durst S (2015) Knowledge management in environmental sustainability practices of third-party logistics service providers. Vine 45:509-529
Facchini F, Olésków-Szłapka J, Ranieri L, Urbinati A (2020) A maturity model for logistics 4.0: an empirical analysis and a roadmap for future research. Sustainability (switzerland) 12:1-18

Felstead M (2019) Cyber-physical production systems in industry 4.0: Smart factory performance, innovation-driven manufacturing process innovation, and sustainable supply chain networks. Econ Manag Financ Mark 14:37-43

Foidl H, Felderer M (2015) Research challenges of industry 4.0 for quality management. In Internationalconference on enterprise resource planning systems. Springer, Cham, pp 121-137

Frontoni E, Rosetti R, Paolanti M, Alves AC (2020) HATS project for lean and smart global logistic: a shipping company case study. Manuf Lett 23:71-74

Furstenau LB, Sott MK, Kipper LM, Machado EL, Lopez-Robles JR, Dohan MS, Cobo MJ, Zahid A, Abbasi QH, Imran MA (2020) Link between sustainability and industry 4.0: trends, challenges and new perspectives. Ieee Access 8:140079-140096

Gebresenbet G, Bosona T, Olsson SO, Garcia D (2018) Smart system for the optimization of logistics performance of the pruning biomass value chain. Appl Sci 8(7):1162

Ghobakhloo M (2020) Industry 4.0, digitization, and opportunities for sustainability. J Clean Prod 252:119869

Gonzalez EDRS, Sarkis J, Huisingh D, Huatuco LH, Maculan N, Montoya-Torres JR, de Almeida CMVB (2015) Making real progress toward more sustainable societies using decision support models and tools: Introduction to the special volume. J Clean Prod 105:1-13

Govindan K, Soleimani H, Kannan D (2015) Reverse logistics and closed-loop supply chain: a comprehensive review to explore the future. Eur J Oper Res 240:603-626

Greif T, Stein N, Flath CM (2020) Peeking into the void: Digital twins for construction site logistics. Comput Ind 121:103264

Gružauskas V, Baskutis S, Navickas V (2018) Minimizing the trade-off between sustainability and cost effective performance by using autonomous vehicles. J Clean Prod 184:709-717

Grzybowska K, Awasthi A (2020) Literaturereview on sustainable logistics and sustainable production for Industry4.0. Sustainable Logistics and Production in Industry 4.0, pp1-18

Gunal MM (2019) Data Collection InsideIndustrial Facilities with Autonomous Drones. In Simulation for Industry 4.0. Springer, Cham, pp 141-151

Gupta SM (ed) (2019) Reverse supplychains: issues and analysis. CRC Press, Boca Raton, Florida

Hasan MM, Jiang D, Ullah AS, Noor-E-Alam M (2020) Resilient supplier selection in logistics 4.0 withheterogeneous information. Expert Syst Appl 139:112799

Helm JM, Swiergosz AM, Haeberle HS, Karnuta JM, Schaffer JL, Krebs VE, Spitzer AI, Ramkumar PN (2020) Machine learning and artificial intelligence: definitions, applications, and future directions. Curr Rev Musculoskelet Med 13(1):69-76

Hilpert H, Kranz J, Schumann M (2013) Leveraging green is in logistics: Developing an artifact for greenhouse gas emission tracking. Bus Inf Syst Eng 5:315-325

Hoffa-Dabrowska P, Grzybowska K (2020) Simulation modeling of the sustainable supply chain. Sustainability 12(15):6007

Hong J, Alzaman C, Diabat A, Bulgak A (2019) Sustainability dimensions and PM 2.5 in supply chain logistics. Ann Oper Res 275:339-366

Hsiao WH, Chang TS (2019) Exploring the opportunity of digital voice assistants in the logistics and transportation industry. J Enterp Inf Manag 32:1034-1050

Isasi-Sanchez L, Morcillo-Bellido J, Ortiz-Gonzalez JI, Duran-Heras A (2020) Synergic sustainability implications of additive manufacturing in automotive spare parts: a case analysis. Sustainability (switzerland) 12:1-18 
Issaoui Y, Khiat A, Bahnasse A, Ouajji H (2021) Toward smart logistics: engineering insights and emergingtrends. Arch Comput Methods Eng 28(4):3183-3210

Ivanov D, Dolgui A (2020) A digitalsupply chain twin for managing the disruption risks and resilience in the eraof Industry 4.0. Prod Plan Control 32(9):775-788

Jabbar S, Khan M, Silva BN, Han K (2018) A REST-based industrial web of things' framework for smart warehousing. J Supercomput 74:4419-4433

Jagtap S, Bader F, Garcia-Garcia G, Trollman H, Fadiji T, Salonitis K (2021) Food logistics 4.0: opportunities and challenges. Logistics 5:2

Jahani N, Sepehri A, Vandchali HR, Tirkolaee EB (2021) Application of Industry 4.0 in the procurement processes of supply chains: a systematic literature review. Sustainability 13:7520

Karakikes I, Nathanail E (2017) Simulation techniques for evaluating smart logistics solutions for sustainable urban distribution. Procedia Eng 178:569-578

Kazemi N, Modak NM, Govindan K (2019) A review of reverse logistics and closed loop supply chain management studies published in IJPR: a bibliometric and content analysis. Int J Prod Res 57:4937-4960

Khorram Niaki M, Nonino F (2017) Additive manufacturing management: a review and future research agenda. Int J Prod Res 55:1419-1439

Kitchenham B (2004) Procedures for performing systematic reviews. Keele, UK, Keele University 33:1-26

Kodym O, Kubáč L, Kavka L (2020) Risks associated with Logistics 4.0 and their minimization using Blockchain. Open Eng 10:74-85

Kouhizadeh M, Saberi S, Sarkis J (2021) Blockchain technology and the sustainable supply chain: Theoretically exploringadoption barriers. Int J Prod Econ 231:107831

Krykavskyy Y, Pokhylchenko O, Hayvanovych N (2019) Supply chain development drivers in industry 4.0 in Ukrainian enterprises. Oecon Copernic 10:273-290

Kucukaltan B, Saatcioglu OY, Irani Z, Tuna O (2020) Gaining strategic insights into Logistics 4.0: expectations andimpacts. Prod Plan Control, pp.1-17. https://doi.org/10.1080/09537287.2020. 1810760

Kumar P, Singh RK, Kumar V (2021) Managing supply chains for sustainable operations in the era of industry 4.0and circular economy: Analysis of barriers. Resour Conserv Recycl 164:105215

La Scalia G, Nasca A, Corona O, Settanni L, Micale R (2017) An innovative shelf life model based on smart logisticunit for an efficient management of the perishable food supply chain. J Food Process Eng 40(1):e12311

Larson PD, Halldorsson A (2004) Logistics versus supply chain management: an international survey. Int J Log Res Appl 7:17-31

Lasi H, Fettke P, Kemper HG, Feld T, Hoffmann M (2014) Industry 4.0. Bus Inf Syst Eng 6(4):239-242

Lee CKM, Lv Y, Ng KKH, Ho W, Choy KL (2018) Design and application of internet of things-based warehouse management system for smart logistics. Int J Prod Res 56:2753-2768

Lee S, Kang Y, Prabhu VV (2016) Smart logistics: distributed control of green crowdsourced parcel services. Int J Prod Res 54:6956-6968

Li J, Fang H, Song W (2019) Sustainable supplier selection based on SSCM practices: a rough cloud TOPSIS approach. J Clean Prod 222:606-621

Li Z, Wang Y, Wang K-S (2017) Intelligent predictive maintenance for fault diagnosis and prognosis in machine centers: Industry 4.0 scenario. Adv Manuf 5:377-387

Lin N, Shi Y, Zhang T, Wang X (2019) An effective order-aware hybrid genetic algorithm for capacitated vehicle routing problems in internet of things. IEEE Access 7:86102-86114
Liu W, Wei W, Yan X, Dong D, Chen Z (2020) Sustainability risk management in a smart logistics ecological chain:An evaluation framework based on social network analysis. J Clean Prod 276:124189

Liu W, Zhang J, Wei S, Wang D (2021) Factors influencing organisational efficiency in a smart-logistics ecological chainunder e-commerce platform leadership. Int J Logist Res Appl 24(4):364-391

Liu X (2015) A research on the developing route and model structuring for logistical public information platform of "smart Zhuzhou" in circumstance of big data. Metall Min Ind 7:1036-1045

Liu X, Cao J, Yang Y, Jiang S (2018) CPS-based smart warehouse for industry 4.0: a survey of the underlying technologies. Computers 7:13

Longo F (2012) Sustainable supply chain design: an application example in local business retail. Simulation 88:1484-1498

Lummus RR, Krumwiede DW, Vokurka RJ (2001) The relationship of logistics to supply chain management: developing acommon industry definition. Ind Manag Data Syst 101(8):426-431

Luo C, Fu Q (2017) Smart logistics monitoring system for hazardous chemicals based on wireless sensor technology. Chem Eng Trans 62:787-792

Luthra S, Mangla SK (2018) Evaluating challenges to Industry 4.0 initiatives for supply chain sustainability in emerging economies. Process Saf Environ Prot 117:168-179

Lv Y, Xiang S, Zhu T, Zhang S (2020) Data-driven design and optimization for smart logistics parks: Towards thesustainable development of the steel industry. Sustainability 12(17):7034

Ma K, Wang L, Chen Y (2018) Acollaborative cloud service platform for realizing sustainable make-to-orderapparel supply chain. Sustainability 10(1):11

Ma X, Wang J, Bai Q, Wang S (2020) Optimization of a three-echelon cold chain considering freshness-keepingefforts under cap-andtrade regulation in Industry 4.0. Int J Prod Econ 220:107457

Manavalan E, Jayakrishna K (2019) A review of Internet of Things (IoT) embedded sustainable supply chain for industry 4.0 requirements. Comput Ind Eng 127:925-953

Manupati VK, Schoenherr T, Ramkumar M, Wagner SM, Pabba SK, INDER RAJ SINGH, R. (2020) A blockchain-based approach for a multi-echelon sustainable supply chain. Int J Prod Res 58:2222-2241

Marchi B, Zanoni S (2017) Supply chain management for improved energy efficiency: Review and opportunities. Energies 10:1618

Margherita EG, Braccini AM (2020)Organizational Impacts on Sustainability of Industry 4.0: A SystematicLiterature Review from Empirical Case Studies. In: Agrifoglio R., Lamboglia R.,Mancini D., Ricciardi F. (eds) Digital Business Transformation. Lecture Notesin Information Systems and Organisation, vol 38. Springer, Cham. https://doi.org/10.1007/978-3-030-47355-6_12

Martins VWB, Anholon R, Sanchez-Rodrigues V, Leal Filho W, Quelhas OLG (2020) Brazilian logisticspractitioners' perceptions on sustainability: an exploratory study. Int J Logist Manag 32(1):190-213

Mastos TD, Nizamis A, Vafeiadis T,Alexopoulos N, Ntinas C, Gkortzis D, Papadopoulos A, Ioannidis D, Tzovaras D (2020) Industry 4.0 sustainable supply chains: An application ofan IoT enabled scrap metal management solution. J Clean Prod 269:122377

Matlou OG, Abu-Mahfouz AM (2017) Utilising artificial intelligence in software defined wireless sensornetwork. In IECON 2017 43rd Annual Conference of the IEEE IndustrialElectronics Society (pp. 6131-6136). IEEE

Mehmann J, Teuteberg F (2016) The fourth-party logistics service provider approach to support sustainable development goals in transportation - a case study of the German agricultural bulk logistics sector. J Clean Prod 126:382-393 
Morella P, Lambán MP, Royo J, Sánchez JC, Corrales LCN (2020) Development of a new green indicator and its implementation in a cyber-physical system for a green supply chain. Sustainability (switzerland) 12:1-19

Motevalli-Taher F, Paydar MM, Emami S (2020) Wheat sustainable supply chain network design with forecasted demand by simulation. Comput Electron Agric 178:105763

Munsamy M, Telukdarie A, Dhamija P (2020) Logistics 4.0 energy modelling. Int J Bus Anal 7:98-121

Murphy PR, Poist RF (2003) Greenperspectives and practices: a "comparative logistics" study. Int J Supply Chain Manag 8(2):122-131

Nenni ME, Sforza A, Sterle C (2019) Sustainability-based review of urban freight models. Soft Comput 23:2899-2909

Nica E (2019) Cyber-physical production networks and advanced digitalization in industry 4.0 manufacturing systems: sustainable supply chain management, organizational resilience, and data-driven innovation. J Self-Gov Manag Econ 7:27-33

Olsen TL, Tomlin B (2020) Industry 4.0: Opportunities and challenges for operations management. Manuf Serv Oper Manag 22:113-122

Pan X, Li M. Wang M, Zong T, Song M (2020) The effects of a Smart Logistics policy on carbon emissions in China: A difference-in-differences analysis. Transp Res E: Logist Transp Rev 137:101939

Pesapane F, Codari M, Sardanelli F (2018) Artificial intelligence in medical imaging: threat or opportunity? Radiologists again at the forefront of innovation in medicine. Eur Radiol Exp 2:35

Phuyal S, Bista D, Bista R (2020) Challenges, opportunities and future directions of smart manufacturing: a state of art review. Sustainable Futures 2:100023

Prause G (2015) Sustainable business models and structures for industry 4.0. J Secur Sustain Issues 5:159-169

Prause G, Atari S (2017) On sustainable production networks for industry 4.0. Entrep Sustain Issues 4:421-431

Qaiser FH, Ahmed K, Sykora M, Choudhary A, Simpson M (2017) Decision support systems for sustainable logistics: a review \& bibliometric analysis. Ind Manag Data Syst 117:1376-1388

Qin J, Liu Y, Grosvenor R (2016) A categorical framework of manufacturing for industry 4.0 and beyond. Procedia Cirp 52:173-178

Rakyta M, Fusko M, Herčko J, Závodská L, Zrnić N (2016) Proactive approach to smart maintenance and logistics as a auxiliary and service processes in a company. J Appl Eng Sci 14:433-442

Ranieri L, Digiesi S, Silvestri B, Roccotelli M (2018) A review of last mile logistics innovations in an externalities cost reduction vision. Sustainability 10(3):782

Rauter R, Jonker J, Baumgartner RJ (2017) Going one's own way: drivers in developing business models for sustainability. J Clean Prod 140:144-154

Reddy KRK, Gunasekaran A, Kalpana P, Sreedharan VR, Kumar SA (2021) Developing a Blockchain Framework forthe Automotive Supply Chain: A systematic Review. Comput Ind Eng 157:107334

Rejeb A, Rejeb K (2020) Blockchain and Supply Chain Sustainability Logforum 16:363-372

Ren R, Hu W, Dong J, Sun B, Chen Y, Chen Z (2020) A systematic literature review of green and sustainablelogistics: bibliometric analysis, research trend and knowledge taxonomy. Int J Environ Res Public Health 17(1):261

Riahi Y, Saikouk T, Gunasekaran A, Badraoui I (2021) Artificial intelligence applications in supply chain: a descriptive bibliometric analysis and future research directions. Expert Syst. Appl. 173:114702

Robert KW, Parris TM, Leiserowitz AA (2005) What is sustainable development? Goals, indicators, values, and practice. Environment: science and policy for sustainable development 47:8-21
Roblek V, Thorpe O, Bach MP, Jerman A, Meško M (2020) The fourth industrial revolution and the sustainability practices: a comparative automated content analysis approach of theory and practice. Sustainability 12:8497

Rojko A (2017) Industry 4.0 concept: Background and overview. Int J Interact Mob Technol 11:77-90

Saberi S, Kouhizadeh M, Sarkis J, Shen L (2019) Blockchain technology and its relationships to sustainable supply chain management. Int J Prod Res 57:2117-2135

Sahay N, Ierapetritou M (2013) Supply chain management using an optimization driven simulation approach. AIChE J 59:4612-4626

Samir T, Abdelsamad C, Aziz S, Jamila E (2019) Big data research on the green internet of things in new smart-logistics. IJITEE 8:534-537

Sciortino R, Micale R, Enea M, la Scalia G (2016) A webGIS-based system for real time shelf life prediction. Comput Electron Agric 127:451-459

Sheares G (2020) Smart logistics and data-driven decision-making processes in cyber-physical manufacturing systems. Econ Manag Financ Mark 15:33-39

Shoaib M, Lim MK, Wang C (2020) An integrated framework to prioritize blockchain-based supply chain success factors. Ind Manag Data Syst 120:2103-2131

Sivamani S, Kwak K, Cho Y (2014) Astudy on intelligent usercentric logistics service model using ontology. J Appl Math 2014:162838

Solvang WD, Deng Z, Solvang B (2007) A closed-loop supply chain model formanaging overall optimization of eco-efficiency. In POMS 18th Annual Conference. Dallas Texas,USA.

Sony M, Naik SS (2019) Ten lessons for managers while implementing Industry 4.0. IEEE Eng Manage Rev 47:45-52

Stevenson A (2010) Oxford dictionary of English. Oxford University Press, USA

Stolaroff JK, Samaras C, O'Neill ER, Lubers A, Mitchell AS, Ceperley D (2018) Energy use and life cycle greenhouse gas emissions of drones for commercial package delivery. Nat Commun 9:1-13

Strandhagen JO, Vallandingham LR, Fragapane G, Strandhagen JW, Stangeland ABH, Sharma N (2017) Logistics 4.0 and emerging sustainable business models. Adv Manuf 5:359-369

Su Y, Fan QM (2019) The green vehiclerouting problem from a smart logistics perspective. IEEE Access 8:839-846

Sun X, Yu H, Solvang WD (2020) Industry 4.0 and Sustainable Supply Chain Management. In International Workshop of Advanced Manufacturing and Automation. Springer, Singapore, pp 595-604

Sun Y, Zhang C, Dong K, Lang M (2018) Multiagent modelling and simulation of a physical internet enabled rail-road intermodal transport system. Urban Rail Transit 4:141-154

Sundarakani B, Lai YS, Goh M, de Souza R (2019) Studying the sustainability of third party logistics growth using system dynamics. J Model Manag 14:872-895

Sutawijaya AH, Nawangsari LC (2020) What is the impact of industry 4.0 to green supply chain? J Environ Treat Tech 8:207-213

Tang X (2020) Research on smart logistics model based on internet of things technology. IEEE Access 8:151150-151159

Tang Z, Liu X, Wang Y (2020) Integratedoptimization of sustainable transportation and inventory with multiplayerdynamic game under carbon tax policy. Math Probl Eng 2020:4948383

Tatham P, Stadler F, Murray A, Shaban RZ (2017) Flying maggots: a smart logistic solution to an enduring medical challenge. $\mathrm{J}$ Humanit Logist Supply Chain Manag 7:172-193

TenHompel M, Schmidt T (2008) Warehouse management. SpringerBerlin Heidelberg

Teucke M, Broda E, Boerold A, Freitag M (2018) Using sensor-based quality data in automotive supply chains. Machines 6(4),p.53 
Tijan E, Aksentijević S, Ivanić K, Jardas M (2019) Blockchain technology implementation in logistics. Sustainability 11(4):1185

Tirkolaee EB, Sadeghi S, Mooseloo FM,Vandchali HR, Aeini S (2021) Application of Machine Learning in SupplyChain Management: A Comprehensive Overview of the Main Areas. Math Probl Eng 2021:1476043

Trab S, Bajic E, Zouinkhi A, Thomas A, Abdelkrim MN, Chekir H, Ltaief RH (2017) A communicating object's approach for smart logistics and safety issues in warehouses. Concurr Eng Res Appl 25:53-67

Trappey AJC, Trappey CV, Fan CY, Hsu APT, Li XK, Lee IJY (2017) IoT patent roadmap for smart logistic service provision in the context of Industry 4.0. J Chin Inst Eng Trans Chin Inst Eng, Series A 40:593-602

Tseng ML, Wu KJ, Lim MK, Wong WP (2019a) Data-driven sustainable supply chain management performance: a hierarchical structure assessment under uncertainties. J Clean Prod 227:760-771

Tseng SH, Wee HM, Song PS, Jeng S (2019b) Optimal green supply-chain model design considering full truckload. Kybernetes 48:2150-2174

Tuffnell C, Kral P, Durana P, Krulicky T (2019) Industry 4.0-based manufacturing systems: smart production, sustainable supply chain networks, and real-time process monitoring. J Self-Gov Manag Econ 7:7-12

UN 2015. Sustainable development goals. Accessed on: https://www. un.org/sustainabledevelopment/ [25.05.2020]

Wang G, Gunasekaran A, Ngai EWT, Papadopoulos T (2016) Big data analytics in logistics and supply chain management: certain investigations for research and applications. Int J Prod Econ 176:98-110

Wang K (2016) Logistics 4.0 solution-newchallenges and opportunities. In 6th International Workshop of AdvancedManufacturing and Automation (pp. 68-74). Atlantis Press, Paris

Wang XV, Wang L (2019) Digital twin-based WEEE recycling, recovery and remanufacturing in the background of Industry 4.0. Int J Prod Res 57:3892-3902

Wang Y, Ma H-S, Yang J-H, Wang K-S (2017) Industry 4.0: a way from mass customization to mass personalization production. Adv Manuf 5:311-320

Wanke P, Correa H, Jacob J, Santos T (2015) Including carbon emissions in the planning of logistic networks: a Brazilian case. Int J Shipp Transp Logist 7:655-675

Wen J, He L, Zhu F (2018) Swarm robotics control and communications: imminent challenges for next generation smart logistics. IEEE Commun Mag 56:102-107

Winkelhaus S, Grosse EH (2020) Logistics 4.0: a systematic review towards a new logistics system. Int J Prod Res 58:18-43

Xia F, Yang LT, Wang L, Vinel A (2012) Internet of things. Int J Commun Syst 25:1101

XIE, G. (2018) Smart logistics management of hazardous chemicals based on internet of things. Chem Eng Trans 67:85-90
Xu J, Jiao Y, Yuan Y (2013) Constructing and the related key techniques for the smart logistics information platform of Yiwu Port. J Theor Appl Inf Technol 51:482-488

Yadav G, Luthra S, Jakhar SK, Mangla SK, Rai DP (2020) A framework to overcome sustainable supply chainchallenges through solution measures of industry 4.0 and circular economy: Anautomotive case. J Clean Prod 254:120112

Yadav, S. and Singh, S.P., (2020) Blockchaincritical success factors for sustainable supply chain. Resour Conserv Recycl 152:104505

Yang J, Guizani N, Hu L, Ghoneim A, Alrashoud M, SHAMIM HOSSAIN, M. (2020) Smart Autonomous Moving Platforms. IEEE Network 34:116-123

Yavas V, Ozkan-Ozen YD (2020) Logistics centersin the new industrial era: A proposed framework for logistics center 4.0. Transp Res E: Logist Transp Rev 135:101864

Yu H, Solvang WD (2016) A general reverse logistics network design model for product reuse and recycling with environmental considerations. Int J Adv Manuf Technol 87:2693-2711

Yu H, Solvang WD (2017) Enhancingthe competitiveness of manufacturers through Small-scale IntelligentManufacturing System (SIMS): A supply chain perspective. In 2017 6thInternational Conference on Industrial Technology and Management (ICITM) (pp.101-107). IEEE

Yu H, Solvang WD (2020) Afuzzy-stochastic multi-objective model for sustainable planning of aclosed-loop supply chain considering mixed uncertainty and networkflexibility. J Clean Prod 266:121702

Yu H, Sun X, Solvang WD, Laporte G, Lee CKM (2020) A stochastic network design problem for hazardous waste management. J Clean Prod 277:123566

Yu YW, Jung H, Bae H (2015) Integrated GIS-based logistics process monitoring framework with convenient work processing environment for smart logistics. ETRI J 37:306-316

Zhang A, Zhong RY, Farooque M, Kang K, Venkatesh VG (2020) Blockchain-based life cycle assessment: Animplementation framework and system architecture. Resour Conserv Recycl 152:104512

Zhang N (2018) Smart logistics path for cyber-physical systems with internet of things. IEEE Access 6:70808-70819

Zhang Y, Liu S, Liu Y, Li R (2016) Smart box-enabled product-service system for cloud logistics. Int J Prod Res 54:6693-6706

Zhao Z, Zhang M, Xu G, Zhang D,Huang GQ (2020) Logistics sustainability practices: an IoT-enabled smartindoor parking system for industrial hazardous chemical vehicles. Int J Prod Res 58(24):7490-7506

Zhou W, Piramuthu S, Chu F, Chu C (2017) RFID-enabled flexible warehousing. Decis Support Syst 98:99-112

Zissis D, Aktas E, Bourlakis M (2018) Collaboration in urban distribution of online grocery orders. Int J Logist Manag 29:1196-1214

Publisher's note Springer Nature remains neutral with regard to jurisdictional claims in published maps and institutional affiliations. 